\title{
Heparan Sulfate Sulfation by Hs2st Restricts Astroglial Precursor Somal Translocation in Developing Mouse Forebrain by a Non-Cell-Autonomous Mechanism
}

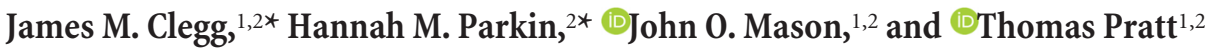 \\ ${ }^{1}$ Simons Initiative for the Developing Brain, and ${ }^{2}$ Centre for Discovery Brain Sciences, Edinburgh Medical School: Biomedical Sciences, The University of \\ Edinburgh, Edinburgh EH8 9XD, United Kingdom
}

\begin{abstract}
Heparan sulfate (HS) is a cell surface and extracellular matrix carbohydrate extensively modified by differential sulfation. HS interacts physically with canonical fibroblast growth factor (FGF) proteins that signal through the extracellular signal regulated kinase (ERK)/ mitogen activated protein kinase (MAPK) pathway. At the embryonic mouse telencephalic midline, FGF/ERK signaling drives astroglial precursor somal translocation from the ventricular zone of the corticoseptal boundary (CSB) to the induseum griseum (IG), producing a focus of Slit2-expressing astroglial guidepost cells essential for interhemispheric corpus callosum (CC) axon navigation. Here, we investigated the cell and molecular function of a specific form of HS sulfation, 2-0 HS sulfation catalyzed by the enzyme Hs2st, in midline astroglial development and in regulating FGF protein levels and interaction with HS. Hs2st ${ }^{-1-}$ embryos of either sex exhibit a grossly enlarged IG due to precocious astroglial translocation and conditional $H s 2 s t$ mutagenesis and ex vivo culture experiments show that $H s 2 s t$ is not required cell autonomously by CC axons or by the IG astroglial cell lineage, but rather acts non-cell autonomously to suppress the transmission of translocation signals to astroglial precursors. Rescue of the $\mathrm{Hs} 2 \mathrm{st}^{-\mathrm{I}^{-}}$astroglial translocation phenotype by pharmacologically inhibiting FGF signaling shows that the normal role of Hs2st is to suppress FGF-mediated astroglial translocation. We demonstrate a selective action of Hs2st on FGF protein by showing that Hs2st (but not Hs6st1) normally suppresses the levels of Fgf17 protein in the CSB region in vivo and use a biochemical assay to show that $H s 2 s t$ (but not Hs6st1) facilitates a physical interaction between the Fgf17 protein and HS.
\end{abstract}

Key words: corpus callosum; FGF; heparan sulfate; mosaic; paracrine; telencephalon

Significance Statement

We report a novel non-cell-autonomous mechanism regulating cell signaling in developing brain. Using the developing mouse telencephalic midline as an exemplar, we show that the specific sulfation modification of the cell surface and extracellular carbohydrate heparan sulfate (HS) performed by Hs2st suppresses the supply of translocation signals to astroglial precursors by a non-cell-autonomous mechanism. We further show that Hs2st modification selectively facilitates a physical interaction between Fgf17 and HS and suppresses Fgf17 protein levels in vivo, strongly suggesting that Hs2st acts selectively on Fgf17 signaling. HS interacts with many signaling proteins potentially encoding numerous selective interactions important in development and disease, so this class of mechanism may apply more broadly to other biological systems.

\section{Introduction}

The corpus callosum (CC) axon tract connects the cerebral hemispheres through the corticoseptal boundary (CSB) in mice and humans and CC malformation is associated with cognitive and neurological conditions in humans (Donahoo and Richards, 2009). Precisely controlled radial glial cell (RGC) somal translo-

\footnotetext{
Received June 22, 2017; revised Dec. 5, 2018; accepted Dec. 11, 2018.

Author contributions: J.M.C., H.M.P., J.O.M., and T.P. designed research; J.M.C. and H.M.P. performed research; J.M.C. and H.M.P. analyzed data; J.M.C., H.M.P., and T.P. wrote the paper.

This work was supported by the Wellcome Trust (Grant 094832/Z/10/Z to T.P.), the Biotechnology and Biological Sciences Research Council (BBSRC Grant BB/M00693X/1 to T.P.), and an EASTBI0 BBSRC-funded doctoral studentship to H.M.P. We thank Jeffrey Esko (University College San Diego) for Hs $2 s t^{f l}$, Yu Yamaguchi (Sanford Burnham Institute) for Ext $1^{\mathrm{fl}}$, Nicoletta Kessaris (University College London) for Zic4 ${ }^{\mathrm{Cre}}$ and $\mathrm{Em}_{\mathrm{m}} 1^{\mathrm{CreER}}$, and the anonymous reviewers whose comments have helped us improve the manuscript from its initial submission.
}

The authors declare no competing financial interests.

*J.M.C. and H.M.P. contributed equally to this work.

Correspondence should be addressed to Thomas Pratt at t.pratt@ed.ac.uk.

https://doi.org/10.1523/JNEUROSCI.1747-17.2018

Copyright $\odot 2019$ Clegg et al.

This is an open-access article distributed under the terms of the Creative Commons Attribution License Creative Commons Attribution 4.0 International, which permits unrestricted use, distribution and reproduction in any medium provided that the original work is properly attributed. 
cation from the ventricular zone (VZ) of the CSB to its pial surface generates midline zipper (MZ) and indusium griseum (IG) astroglial populations required for cerebral hemisphere fusion and subsequent CC axon navigation (Shu and Richards, 2001; Inatani et al., 2003; Shu et al., 2003; Smith et al., 2006; Moldrich et al., 2010; Clegg et al., 2014; Gobius et al., 2016). The movement of RGC astroglial precursors from the glial wedge (GW) to the IG (GW $\rightarrow$ IG translocation) forms an astroglial guidepost population that secretes Slit2 to guide CC axons across the telencephalic midline.

Fibroblast growth factors (FGFs) are an evolutionarily ancient family comprising 23 genes in mice and humans of which 15 (Fgf1-10, Fgf16-18, Fgf20, and Fgf22 in mice) encode "canonical" FGFs that function as paracrine signaling molecules and bind promiscuously to cell surface FGF receptors (FGFRs encoded by Fgfr1-4 in mice) to elicit an extracellular signal regulated kinase $(\mathrm{ERK}) /$ mitogen activated kinase (MAPK) response via activating phosphorylation of ERK $\rightarrow$ phospo-ERK (pERK). Canonical FGFs are further subdivided into five subfamilies based on phylogeny and $F g f 8$ subfamily members $F g f 8$ and $F g f 17$ are transcribed in the developing CSB in close spatiotemporal proximity posing the question of how they are coordinated (Guillemot and Zimmer, 2011; Ornitz and Itoh, 2015). Under normal conditions, $\mathrm{GW} \rightarrow \mathrm{IG}$ translocation is primarily attributed to Fgf8 and needs to be tightly regulated to ensure that correct numbers of RGCs leave the GW and reach the IG. Deviation above (or below) normal FGF/ERK signaling levels induces too many (or too few) RGCs to translocate with consequent disruption to CC development (Smith et al., 2006; Wang et al., 2012; Clegg et al., 2014; Gobius et al., 2016). Although Fgf17 plays a role in patterning the developing telencephalon, its importance for CC development is less clear and no CC phenotype has been reported in $\mathrm{Fg} f 7^{-1-}$ embryos (Cholfin and Rubenstein, 2007, 2008). Because Fgf8 and Fgf17 are the principal Fgfs transcribed in vicinity of the GW and both activate ERK, mechanisms must exist to keep the total amount of Fgf protein (Fgf8 protein + Fgf17 protein) at the correct level to generate the correct levels of ERK activation for astroglial precursor RGCs to translocate in appropriate numbers.

Heparan sulfate (HS), the carbohydrate component of cell surface and extracellular matrix (ECM) HS proteoglycans, is a negatively charged sulfated polysaccharide that binds canonical FGFs in the ECM to regulate their movement and half-life and also functions as an obligate FGF coreceptor in FGF:FGFR:HS ternary signaling complexes on the cell surface (Guillemot and Zimmer, 2011; Balasubramanian and Zhang, 2016). HS biosynthesis is in two stages, Ext enzymes polymerize uronic acid - glucosamine disaccharides making linear [uronic acid - glucosamine] ${ }_{n}$ HS polymers which are then modified by the enzymatic addition (by HS sulfotransferases, HSTs) or removal (by HS sulfatases, Sulfs) of sulfate groups at specific positions on the disaccharide residues. There are four classes of HST enzymes, Hs2st, Hs3st, Hs6st, and Ndst, each adding sulfate to a specific position; for example, Hs2st only adds sulfate to the carbon atom in position 2 of uronic acid, generating 2-O HS sulfation. Although work in a variety of systems shows that HS itself can play roles both in the transmission of FGF signals through the ECM (non-cell-autonomous role) and the cellular response to FGF (cell-autonomous role), the potential for specific forms of HS sulfation to selectively regulate FGFs by regulating the physical interaction between HS and FGF proteins is much less well understood (Allen et al., 2001; Loo et al., 2001; Loo and Salmivirta, 2002; Allen and Rapraeger, 2003; Belenkaya et al., 2004; Kinnunen et al., 2005; Makarenkova et al., 2009; Yan and Lin, 2009; Yu et al., 2009; Guillemot and Zimmer,
2011; Qu et al., 2011, 2012; Toyoda et al., 2010; Christian, 2012; Zhang H et al., 2012; Ramsbottom et al., 2014; Chan et al., 2015, 2017; Balasubramanian and Zhang, 2016).

The HS code hypothesis states that different forms of HS sulfation can encode specific instructions (Turnbull et al., 2001; Kreuger et al., 2006). In this study, we discover that 2-O HS sulfation catalyzed by Hs2st functions non-cell autonomously at the developing telencephalic midline to suppress FGF/ERK signaling that drives the somal translocation of astroglial precursors required for normal CC development. We also present evidence that Hs2st plays a selective role by modulating the physical interaction between Fgf17 protein and HS and selectively suppressing Fgf17 protein levels at the CSB.

\section{Materials and Methods}

Animals. All mice were bred in-house according to Home Office UK legislation and licenses approved by the University of Edinburgh Ethical Review Committees and Home Office. Embryos analyzed in this study were of either sex. Animal husbandry was in accordance with UK Animals (Scientific Procedures) Act of 1986 regulations. The Hs2st LacZ $\left(H s 2 s t^{-}\right)$-null allele comprised a $L a c Z$ gene trap vector integrated into the Hs2st locus, the Hs6st1 LacZiresPLAP $\left(H s 6 s t 1^{-}\right)$-null allele comprised a LacZiresPLAP gene trap vector integrated in the Hs6st1 locus, and both were genotyped by PCR as described previously (Bullock et al., 1998; Pratt et al., 2006; Conway et al., 2011). For some ex vivo experiments, $H s 2 s t^{-1+}$ mice were crossed with mice carrying the TP6.3 tau $(\tau)$-GFP fusion transgene to generate $H s 2 s t^{-1-}$ and $H s 2 s t^{+/+}$embryos with $\tau G F P^{+}$axons (Pratt et al., 2000). For conditional mutagenesis, floxed Ext1 $\left(E x t 1^{\mathrm{fl}}\right)$ or $H s 2 s t\left(H s 2 s t^{\mathrm{fl}}\right)$ alleles were combined with either Zic $4^{\text {Cre }}$ (septal deletion) or Emx ${ }^{\text {CreER }}$ (cortical deletion) driver alleles (Inatani et al., 2003; Kessaris et al., 2006; Rubin et al., 2010; Stanford et al., 2010). CreER activity was induced at embryonic day 9.5 (E9.5) by administering tamoxifen (dissolved in corn oil using a sonicator) to pregnant dams by intraperitoneal injection ( $120 \mathrm{mg} / \mathrm{kg}$ dose). Lineages of cells in which Cre was active were visualized using a Rosa26R-floxedstop-EGFP reporter allele (Sousa et al., 2009).

Ex vivo assays. Ex vivo culture experiments were performed essentially as described previously (Niquille et al., 2009) Explants were cultured on nucleopore polycarbonate membranes (Whatman) floating on $1 \mathrm{ml}$ of neurobasal medium (Life Technologies) supplemented with L-glutamine, glucose, and penicillin/streptomycin) at $37^{\circ} \mathrm{C}$ with $5 \% \mathrm{CO}_{2}$ in a humidified incubator. Brains were dissected from embryos in oxygenated Earle's balanced salt solution (Life Technologies), embedded in lowmelting-point agarose, sliced using a vibratome (Leica VTS-1000), and transferred to modified Eagle's medium (MEM; Life Technologies) with $5 \%$ fetal bovine serum for $1 \mathrm{~h}$. For CC axon navigation assays, $400-\mu \mathrm{m}-$ thick E17.5 coronal slices incorporating the CC axon tract were prepared and frontal cortex explants from $\tau$-GFP ${ }^{+}$slices were transplanted into the equivalent region in $\tau$-GFP ${ }^{-}$slices before culturing in neurobasal medium for $72 \mathrm{~h}$, fixation in $4 \%$ paraformaldehyde (PFA), and GFP immunofluorescence. For glial translocation experiments, $10 \mathrm{mg} / \mathrm{ml}$ BrdU dissolved in PBS was injected intraperitoneally into pregnant dams with E14.5 litters, which were killed $1 \mathrm{~h}$ later and $350 \mu \mathrm{m}$ coronal slices incorporating the CSB prepared for culture. In Fgf17 bead experiments, Affi-Gel blue gel (Bio-Rad) beads presoaked in $100 \mu \mathrm{g} / \mathrm{ml}$ recombinant Fgf17 protein (R\&D systems) or $5 \mathrm{mg} / \mathrm{ml} \mathrm{BSA} \mathrm{(Sigma-Aldrich)} \mathrm{overnight}$ at $4^{\circ} \mathrm{C}$ were implanted into the slice, one Fgf17 and one BSA bead on either side of the midline just below the GW, and the MEM was replaced with neurobasal medium. For the FGFi culture, MEM was replaced with neurobasal medium containing either $25 \mu \mathrm{M}$ SU5402, 0.1\% DMSO (FGFi) or $0.1 \%$ DMSO (control). Slices were cultured for 2 or $48 \mathrm{~h}$, fixed in $4 \%$ PFA, and $10 \mu \mathrm{m}$ frozen sections were prepared for immunodetection or in situ hybridization. Glial migration out of the VZ toward the pial surface was quantified from BrdU/Sox9 immunofluorescence micrographs by demarcating the basal edge of the VZ (easily identified by Sox 9 staining) with a line and counting the number of Sox $9^{+} ; \mathrm{BrdU}^{+}$cells that had crossed this line. This allowed us to count glial $\left(\operatorname{Sox} 9^{+}\right)$cells that had 
incorporated $\mathrm{BrdU}\left(\mathrm{BrdU}^{+}\right)$when they were in the VZ before the start of the culture and subsequently exited the VZ and migrated toward the midline over the $2 \mathrm{~d}$ culture period when the cultures were exposed to experimental substances (SU5402, DMSO, Fgf17 protein, or BSA). Four or six sections were quantified per slice moving rostrally from the most caudal section in which the GW could be identified on both sides of the section.

Immunodetection. Embryonic mouse brains were removed and fixed in $4 \%$ PFA in PBS overnight at $4^{\circ} \mathrm{C}$, cryoprotected in $30 \%$ sucrose in PBS, embedded in OCT, and $10 \mu \mathrm{m}$ coronal frozen sections were cut using a cryostat (Leica). Immunohistochemistry was performed as described previously (Clegg et al., 2014). Primary antibodies: goat anti-GFP (diluted 1/250; Abcam); rabbit anti-Sox9 (1/500; Cell Signaling Technology); rat anti-L1 (1/200; Millipore); rabbit anti-GFAP (1/200 Dako); rabbit anti-Hs2st (1/50; Abcam ab103120); rabbit anti-Fgf17 (1/1000; Abcam ab187982); and rabbit anti-pErk1/2 (1/200; Cell Signaling Technology). Secondary antibodies were as follows: donkey anti-goat Alexa Fluor 488, donkey anti-rabbit Alexa Fluor 568, and goat anti-rat 568 (all used at a dilution of 1/200 and from Invitrogen). Fluorescently labeled sections were counterstained with DAPI (Invitrogen). For Hs2st and pErk1/2 antibody staining, goat anti-rabbit biotin secondary antibody (1/200; Vector Laboratories) was used and staining was visualized using a standard avidin-biotin diaminobenzidine (DAB) staining procedure. The Fgf17 immunofluorescence was performed using exactly the same protocol as described previously for Fgf8 except that the Fgf8 antibody was replaced with the Fgf17 antibody (Toyoda et al., 2010; Clegg et al., 2014). Briefly, slides were first washed in acetone for permeabilization, rabbit Fgf17 antibody was applied, and the TSA Plus Fluorescence System Kit (PerkinElmer) was used for fluorescence detection.

In situ hybridization. In situ hybridization was performed on $10 \mu \mathrm{m}$ frozen sections as described previously (Wallace and Raff, 1999) using digoxigenin-labeled riboprobes for Slit2 and Fgf17 (Xu et al., 1999; Erskine et al., 2000).

Imaging. Fluorescence-labeled sections were imaged using either a Leica AF6000 epifluorescence microscope coupled to a Leica DFC360 digital camera or a Nikon Ti: E Inverted confocal microscope. DAB stained and in situ hybridized sections were imaged using a Leica DLMB microscope coupled to a Leica DFC480 color digital camera.

Fof17 protein quantification. Fgf17 fluorescence was quantified from E14.5 Hs2st ${ }^{+/+} ; H s 6 s t 1^{+/+}, H s 2 s t^{-1-}$, and $H s 6 s t 1^{-1-}$ coronal sections that had been processed for Fgf17 immunofluorescence in parallel and imaged under identical conditions in parallel using the same method as described previously for Fgf8 protein quantification (Chan et al., 2017). For each section, ImageJ was used to measure mean fluorescence intensity in a $100 \times 150 \mu \mathrm{m}$ box drawn at the CSB encompassing the Fgf17 expression domain. For each embryo, quantification was performed for three sections along the rostrocaudal axis and averaged.

IG Sox $9^{+}$cell quantification. Quantification of Sox $9^{+}$cells in the IG region of E18.5 Hs2st ${ }^{\mathrm{fl} / \mathrm{fl}} ; \mathrm{Zic4}{ }^{\mathrm{Cre}}, H s 2 s t^{+/+} ; \mathrm{Zic4}{ }^{\mathrm{Cre}}, H s 2 s t^{\mathrm{fl} / \mathrm{fl}} ; \mathrm{Em} \times \mathrm{l}^{\mathrm{CreER}}$, and $H s 2 s t^{+/+}$;Emxl ${ }^{\text {CreER }}$ embryos was performed as described previously (Clegg et al., 2014). A counting box measuring $200 \times 200 \mu \mathrm{m}$ was placed on images of coronal sections at the midline with the top edge at the dorsal extent of Sox $9^{+}$cells at the IG and the numbers of Sox $9^{+}$cells in the box counted. For each embryo, quantification was performed for three sections along the rostrocaudal axis and averaged.

Western blotting. Western blotting was performed as described previously (Clegg et al., 2014). Primary antibodies were as follows: rabbit anti-Hs2st (1/500; Abcam ab103120) and mouse anti- $\beta$-actin $(1 / 5000$; Abcam). Secondary antibodies were as follows: goat anti-mouse Alexa Fluor 680 (Invitrogen) and goat anti-rabbit 800 (Li-Cor).

Ligand and carbohydrate engagement (LACE) assay. The LACE assay was performed as described previously (Allen et al., 2001; Allen and Rapraeger, 2003; Chan et al., 2015). Briefly, frozen sections were incubated in $0.05 \% \mathrm{NABH}_{4} / \mathrm{PBS}$ for 15 min. After several washes in PBS, sections were incubated in $0.1 \mathrm{M}$ glycine at $4^{\circ} \mathrm{C}$ overnight. Some sections were incubated with Heparitinase I (Seikagaku) before proceeding. All Fgf and Fgfr-Fc proteins were purchased from R\&D Systems. Sections were then treated with $1 \%$ BSA/TBS solution for 10 min before incubation with $3 \mu \mathrm{M}$ recombinant mouse Fgfl7 and $9 \mu \mathrm{M}$ recombinant human
Fgfrla(IIIc)-Fc or 30 nм recombinant mouse Fgf8b and 100 nм recombinant human Fgfr3 (IIIc)-Fc at $4^{\circ} \mathrm{C}$ overnight. Fgf17 or Fgf8 were omitted from some assays. Fluorescent LACE signal was generated by incubation with 1/200 anti-human IgG (Fc-specific) Cy3 (Sigma-Aldrich) in $1 \% \mathrm{BSA} / \mathrm{TBS}$. Hs $2 s t^{+/+} ; H s 6 s t 1^{+/+}, \mathrm{Hs} 2 s \mathrm{t}^{-1-}$, and $H s 6 s t 1^{-1-}$ material that had been processed for each LACE assay condition in parallel was imaged under identical conditions in parallel. For each section, ImageJ was used to measure mean fluorescence intensity in a $100 \times 150 \mu \mathrm{m}$ box drawn encompassing the CSB. Background signal was quantified from control LACE experiments from which the FGF ligand was omitted and these values were used for background subtraction. For each embryo, quantification was performed for three sections along the rostrocaudal axis and averaged.

Data analysis and statistics. Results are expressed as mean \pm SEM. The statistical test and sample size $(n)$ for each experiment are specified in the figure legends. Statistical comparison between two groups was performed with a $t$ test. Statistical comparison between more than two groups was performed with ANOVA followed by post hoc $t$ test. $p<0.05$ was considered significant.

\section{Results}

\section{Hs2st protein is widely expressed in the developing cerebral cortex and at the telencephalic midline}

To establish potential sites of action of Hs 2 st in CC development, we first examined the distribution of cells expressing Hs2st protein and contributing to developing CC structures using Hs2st immunohistochemistry at E14.5 (Fig. $1 A-D$ ) and E18.5 (Fig. $1 E-M)$ spanning the period of CC axon tract development. Macroscopically, Hs2st protein distribution closely resembles the $H s 2 s t-L a c Z$ reporter staining previously reported, with widespread Hs2st expression in the developing cerebral cortex and at the CSB at both E14.5 and E18.5 (Fig. $1 A, E$, boxed areas indicate regions shown at higher magnifications in $B-D$ and $F-M$ ) (Conway et al., 2011). Subcellularly, the Hs2st signal is punctate consistent with the expected localization of Hs2st in the Golgi apparatus (arrows point to Hs2st ${ }^{+}$puncta in higher-magnification insets in Fig. $1 B, F, P)$. At E14.5, there was a high density of $\mathrm{Hs}_{2} \mathrm{st}^{+}$puncta at the CSB in the GW region where IG astroglial RGC prescursors reside (Fig. $1 B$, with boxed area shown as higher-magnification inset with arrows indicating $\mathrm{Hs} 2 \mathrm{st}^{+}$ puncta), with the density falling toward the pial surface although $\mathrm{Hs} 2 \mathrm{st}^{+}$puncta were visible. There were many Hs2st ${ }^{+}$puncta in the VZ of the cerebral cortex (Fig. 1C) and also in the cortical plate (Fig. 1D), indicating that many cortical progenitors and postmitotic neurons express Hs2st. At E18.5, Hs2st is expressed by many cells in the IG (Fig. $1 F$ ) and at the apical surface of the VZ at the GW (Fig. $1 G$ ), septum (Fig. $1 H$ ), and ventral telencephalon (Fig. 1I), with the number of Hs2st expressing VZ cells diminishing as distance from the ventricle increases. In the cerebral cortex, Hs2st is expressed by many cells close to the apical surface of the VZ (Fig. 1J). Large numbers of postmitotic cortical neurons outside of the VZ express Hs2st and, moving toward the pial surface, the density of $\mathrm{Hs} 2 \mathrm{st}^{+}$puncta varies with laminar position [cf. Fig. $1 K-M$, showing relatively high $\mathrm{Hs}_{2} \mathrm{st}^{+}$puncta density in cortical layers adjacent to the pial membrane $(M)$ and in the intermediate zone $(K)$ and lower density in the intervening region $(L)]$. We validated the Hs2st antibody by demonstrating absence of the punctate Hs2st ${ }^{+}$immunostaining in $\mathrm{Hs}_{\mathrm{s}} \mathrm{st} \mathrm{I}^{-1-}$ embryonic material (cf. Fig. $1 N, P$ and $O, Q$; note that the more diffuse staining persists in $H s 2 s t^{-1-}$ tissue and we discounted this as nonspecific background) and Western blot showing that the predicted $42 \mathrm{kDaHs} 2 \mathrm{st}$ protein band was present in $\mathrm{Hs} 2 \mathrm{st}{ }^{+/+}$ and absent from $H s 2 s t^{-1-}$ telencephalic protein extracts (Fig. $1 R)$. To conclude, Hs2st protein is present in developing cerebral cortex, the source of CC axons, as well as in progenitor and post- 


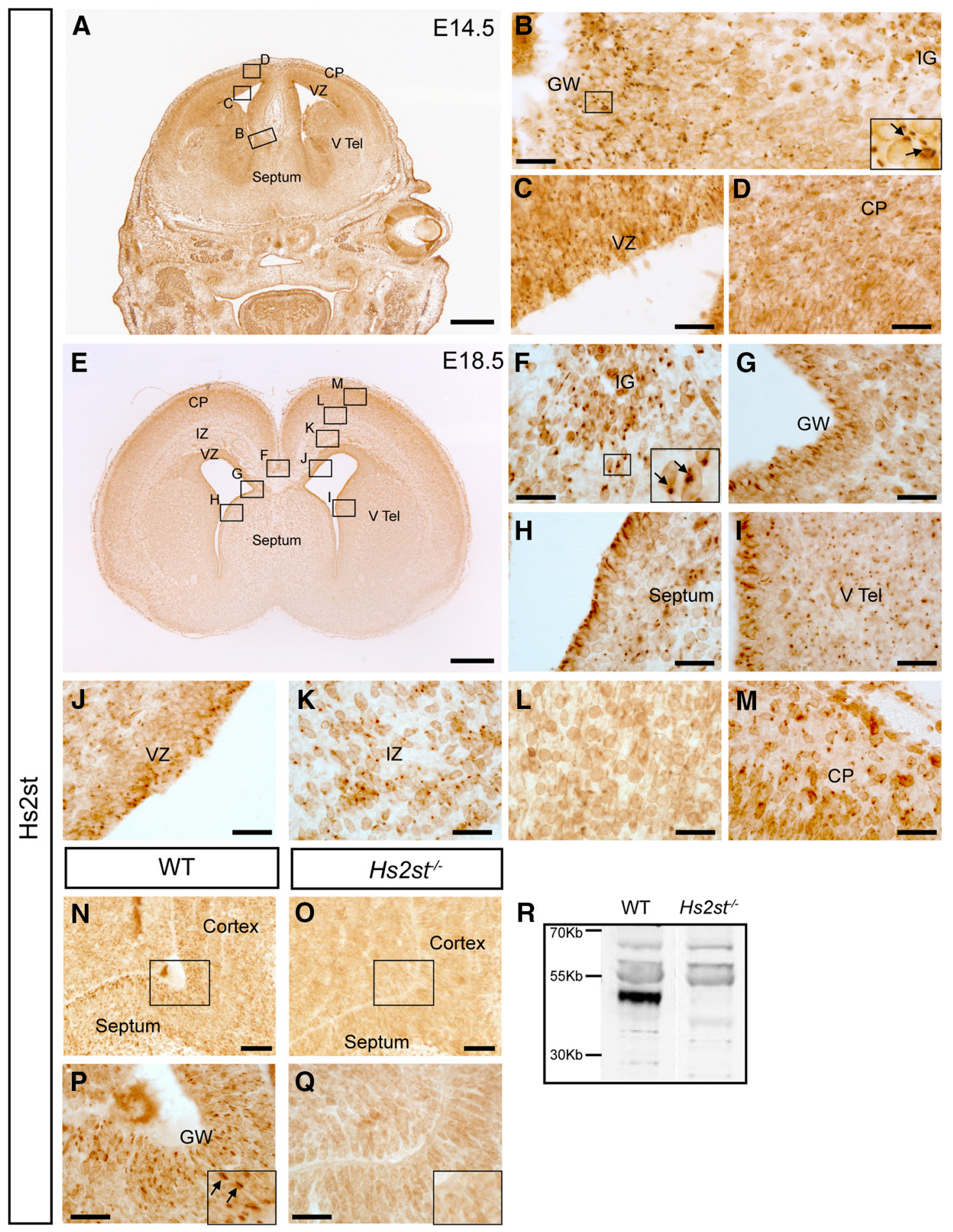

Figure 1. Hs2st protein is expressed in the cerebral cortex and the septum during $\mathrm{CC}$ formation. $\boldsymbol{A}$, Immunohistochemistry for Hs2st at E14.5. B-D, Higher magnification showing punctate

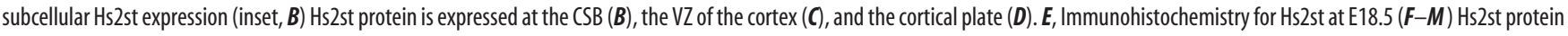
is expressed in the IG $(\boldsymbol{F})$, the GW $(\boldsymbol{G})$, the septum $(\boldsymbol{H})$, and the ventral telencephalon $(\boldsymbol{I})$. Within the cortex, Hs2st is expressed at the VZ $(\boldsymbol{J})$ and the intermediate zone $(\boldsymbol{K})$; Hs2st is not strongly expressed by the middle layers of the cortex $(\boldsymbol{L})$, but is expressed by the deeper layers $(\boldsymbol{M}) . \boldsymbol{N}-\boldsymbol{R}, \mathrm{H} s 2 \mathrm{st}$ antibody specificity. The Hs2st antibody produces signal in the GW (N, $\boldsymbol{P})$, which is lost in $H s 2 s t^{-1-}$ embryos $(\mathbf{O}, \mathbf{Q})$. Western blot performed on protein extracted from whole telencephalon using $\mathrm{Hs} 2 \mathrm{st}$ antibody revealed the predicted $\sim 42 \mathrm{kDa}$ band in WT extracts, which is lost in $\mathrm{H} s 2 \mathrm{t}^{-1-}$ extracts $(\boldsymbol{R}) \cdot \boldsymbol{B}-\boldsymbol{D}$ are higher-magnification images of boxed regions indicated in $\boldsymbol{A} . \boldsymbol{F}-\boldsymbol{M}$ are higher-magnification images of boxed regions indicated in $\boldsymbol{E}$. $\boldsymbol{P}$ and $\mathbf{Q}$ are highermagnification images of boxed regions in $\boldsymbol{N}$ and $\boldsymbol{O}$, respectively. Insets in $\boldsymbol{B}, \boldsymbol{F}, \boldsymbol{P}$ and $\mathbf{Q}$ show higher magnification with arrows indicating Hs 2 st puncta. Scale bars: $\boldsymbol{A}, 500 \mu \mathrm{m} ; \boldsymbol{B}-\boldsymbol{I}, \boldsymbol{L}, \boldsymbol{M}, 50 \mu \mathrm{m} ; \boldsymbol{J}$, $\boldsymbol{K}, 100 \mu \mathrm{m}$.

mitotic cells of the CSB region constituting the environment through which midline crossing CC axons navigate. Hs2st expression analysis suggests multiple potential sites of action for 2-O HS sulfation in CC development.

\section{Slit2-expressing IG is expanded in $\mathrm{Hs} 2 \mathrm{st} \mathrm{t}^{-/-}$embryos}

We previously reported that increased numbers of astroglia at the pial surface of the $\mathrm{Hs}_{\mathrm{S}} \mathrm{st} \mathrm{t}^{-1-} \mathrm{CSB}$ stemmed from precocious glial translocation and found no evidence that changes in cell prolif- 


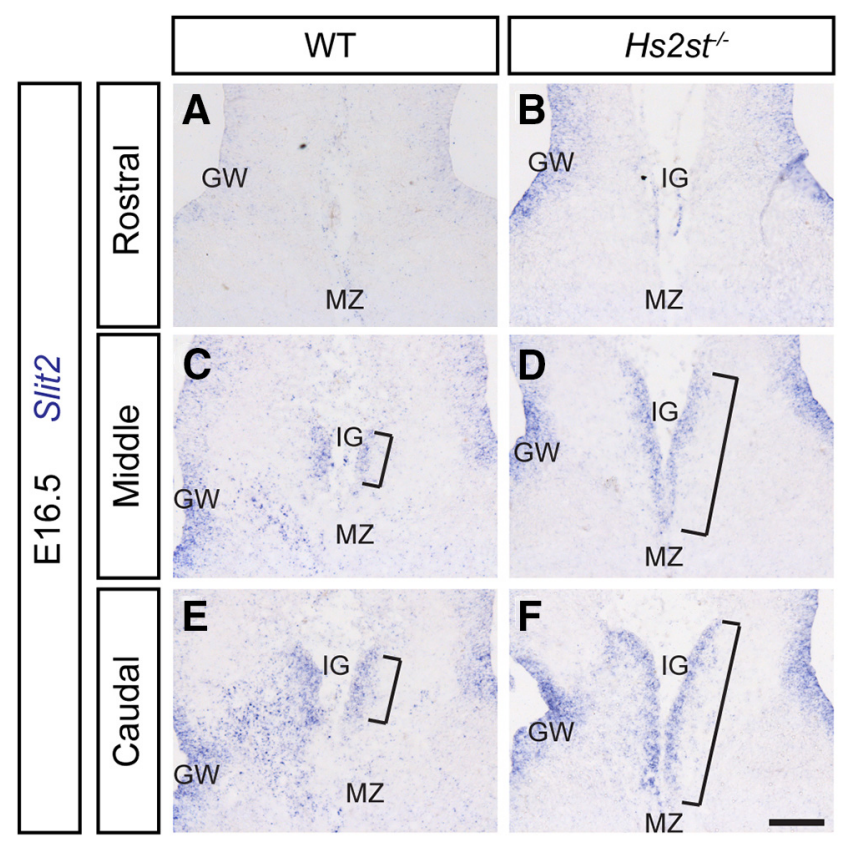

Figure 2. Slit2 expression at the CSB of WT and $H_{s} 2 s t^{-1-}$ embryos at E16.5. A, C, E, In situ hybridization for Slit2 in WT embryos at 3 rostrocaudal positions labeling the GW and IG. B, D, F, In situ hybridization for Slit2 in $\mathrm{Hs}_{\mathrm{s}} \mathrm{st} \mathrm{t}^{-1-}$ embryos at equivalent positions to $\boldsymbol{A}, \boldsymbol{C}$, and $\boldsymbol{E}$, respectively, showing an expanded IG. Scale bars, $100 \mu \mathrm{m}$ in all panels.

eration or death contributed to this phenotype (Conway et al., 2011; Clegg et al., 2014). To determine whether there is an expansion of the IG in $H s 2 s t^{-1-}$ embryos, we compared the expression of Slit2 mRNA, a marker of GW and IG glia but not MZ glia, between $H s 2 s t^{+/+}$and $H s 2 s t^{-1-}$ embryos at E16.5 (Shu and Richards, 2001; Shu et al., 2003). In Hs2st ${ }^{+/+}$embryos Slit2 ${ }^{+}$ cells form a compact focus at the IG that increases in size moving caudally (Fig. 2 A, C, E, Slit2 expression domain at IG indicated by brackets). In $H s 2 s t^{-1-}$ embryos, the Slit2 expression domain is greatly expanded at the pial surface along the rostrocaudal axis (Fig. 2B,D,F, expanded Slit2 expression domain indicated by brackets). We conclude that an expansion of the Slit $2^{+}$IG astroglial population makes a major contribution to the Hs2st ${ }^{-1-}$ phenotype.

\section{Cell autonomy of HS and 2-O HS sulfation in astroglial precursor somal translocation and CC development}

We next exploited conditional mutagenesis of Hs2st or Ext1 to experimentally uncouple specific functions of 2-O sulfation from more general functions of HS in astroglial precursor translocation and CC development. Widespread expression of $\mathrm{HS}$ and 2-O HS sulfation leaves open the possibility that each regulates $\mathrm{GW} \rightarrow \mathrm{IG}$ astroglial precursor somal translocation cell autonomously by modulating the response to signals, non-cell autonomously by regulating the supply of signals, or both. To resolve this, we identified two Cre alleles, Zic4 ${ }^{\text {Cre }}$ and $E m \times 1^{\text {CreER }}$, that drive LoxP-mediated mutagenesis in the astroglial lineage or in their cellular environment, respectively, and used them to conditionally ablate either HS (Ext1 ${ }^{\text {LoxP }}$ mutagenesis) or 2-O HS (Hs2st ${ }^{\text {LoxP }}$ mutagenesis) sulfation to test for cell-autonomous or non-cell-autonomous functions. We refer to these as "Zic4 lineage" and "Emx1 lineage," respectively, and next present their characterization using a floxed-stop GFP reporter that turns on GFP expression in Cre-expressing cells and their descendants before describing experiments where they are used to conditionally generate loss-of-function mutations in $E x t 1^{\mathrm{Fl}}$ or $H s 2 s t^{\mathrm{Fl}}$ alleles (Inatani et al., 2003; Kessaris et al., 2006; Rubin et al., 2010; Sousa et al., 2009; Stanford et al., 2010).

\section{Characterization of Zic4 and Emx 1 lineages}

The septum is of Zic4 lineage, as shown by strong expression of the GFP reporter (Fig. $3 A$ ). The GFP signal in the intermediate zone of the cerebral cortex (asterisks in Fig. 3A) is due to $\mathrm{GFP}^{+}$ thalamocortical axons that project from Zic4-lineage cells in the thalamus and cells of subcortical origin as described previously (Rubin et al., 2010). At the midline, $\mathrm{GFP}^{+}$cells of the Zic4 lineage are predominantly located ventral to the CSB (dashed lines in Fig. $3 B$ ), but there is also GFP expression in the IG (boxed area " $D$ " in Fig. $3 B$ ). Sox9 is a transcription factor that marks the nuclei of RGCs in the VZ and differentiated astroglia in the IG and MZG and we previously showed that the positioning of Sox ${ }^{+}$cells is of critical importance for the development of the CC (Clegg et al., 2014). Combining GFP with Sox9 immunostaining reveals the contribution of the Zic4 lineage to the CSB astroglial populations. There is a sharp boundary (dashed line in Fig. $3 C$ ) in the $\mathrm{VZ}$ of the CSB between Sox $9^{+}$;GFP ${ }^{+}$cells (arrowheads in Fig. $3 C$ ) on the septal side and Sox ${ }^{+}$; $\mathrm{GFP}^{-}$cells (arrows in Fig. $3 C$ ) on the cortical side. Virtually all the Sox $9^{+}$cells in the IG (Fig. 3D) and MZG (Fig. $3 E$ ) are also $\mathrm{GFP}^{+}$(arrowheads in Fig. $3 D, E$ ), indicating that these cells are of the Zic4 lineage. These data show that the Zic4 lineage contributes Sox ${ }^{+}$cells to the septal VZ and, strikingly, is the sole source of Sox ${ }^{+}$astroglia in the IG (Fig. $3 F$ ).

To mark the Emxl lineage, tamoxifen was administered to Emx $1^{\text {CreER }}$ embryos harboring the floxed-stop GFP reporter at E9.5 so that early Emx1 expressing cerebral cortex progenitors and their descendants were rendered GFP ${ }^{+}$. Examination of the expression of the GFP reporter shows that, as expected, the developing cerebral cortex and CC axons are of Emx1 lineage (Fig. $3 G$ ) and that, at the midline, GFP expression is predominantly located dorsal to the CSB (dashed lines in Fig. $3 H$ ). Higher magnification shows that there is a sharp boundary between GFP ${ }^{+}$ and $\mathrm{GFP}^{-}$cells at the VZ of the CSB (dashed line in Fig. 3I). Combining Sox 9 and GFP immunostaining reveals the contribution of the Emx1 lineage to Sox $9^{+}$cells. Sox $9^{+}$; $\mathrm{GFP}^{+}$cells (arrowheads in Fig. $3 I$ ) populate the $\mathrm{VZ}$ on the cortical side of the boundary with Sox $9^{+}$; $\mathrm{GFP}^{-}$cells on the septal side (arrows in Fig. 3I), showing that the Emx1 lineage contributes Sox ${ }^{+}$cells exclusively to the cortical side of the VZ. All Sox $9^{+}$cells in the IG (Fig. $3 J$ ) and $\mathrm{MZ}$ (Fig. $3 K$ ) are $\mathrm{GFP}^{-}$(arrows in Fig. $3 J, K$ ), indicating that the Emx1 lineage does not contribute Sox ${ }^{+}$cells to the IG. These data show that the Emxl lineage contributes Sox $9^{+}$cells to the cortical VZ, but no cells of this lineage contribute Sox $9^{+}$astroglia to the IG (schema in Fig. $3 L$ ).

\section{Ext1 is required by both Emx1- and Zic4-lineage cells for CC development}

To determine the cellular requirement for HS, we deleted Ext1, which is essential for HS synthesis, in the Zic4 or Emx1 lineages. In control embryos, L1 immunostaining labels axons in the U-shaped CC, whereas GFAP staining labels midline astroglial structures (Fig. $4 A$, with higher magnification of IG and GW in $D, G$ ). Removing HS from either the Zic4 lineage (Fig. $4 B$, with higher magnification of IG and GW in Fig. $4 E, H$ ) or the EmxI lineage (Fig. 4C, with higher magnification of IG and GW in Fig. $4 F, I)$ generates a severe CC agenesis phenotype $\left(\right.$ Zic $4^{\mathrm{Cre}} ; E x t 1^{\mathrm{Fl} / \mathrm{Fl}}$ $\left.n=4 / 4 ; E m x 1^{\mathrm{CreER}} ; E x t 1^{\mathrm{Fl} / \mathrm{Fl}} n=3 / 3\right)$. In Emx1 conditional mutants $\left(E m x 1^{\mathrm{CreER}} ; E x t 1^{\mathrm{Fl} / \mathrm{Fl}}\right), \mathrm{CC}$ axons fail to cross the midline and form Probst bundles short of the midline (Fig. 4B). GFAP ${ }^{+}$ 

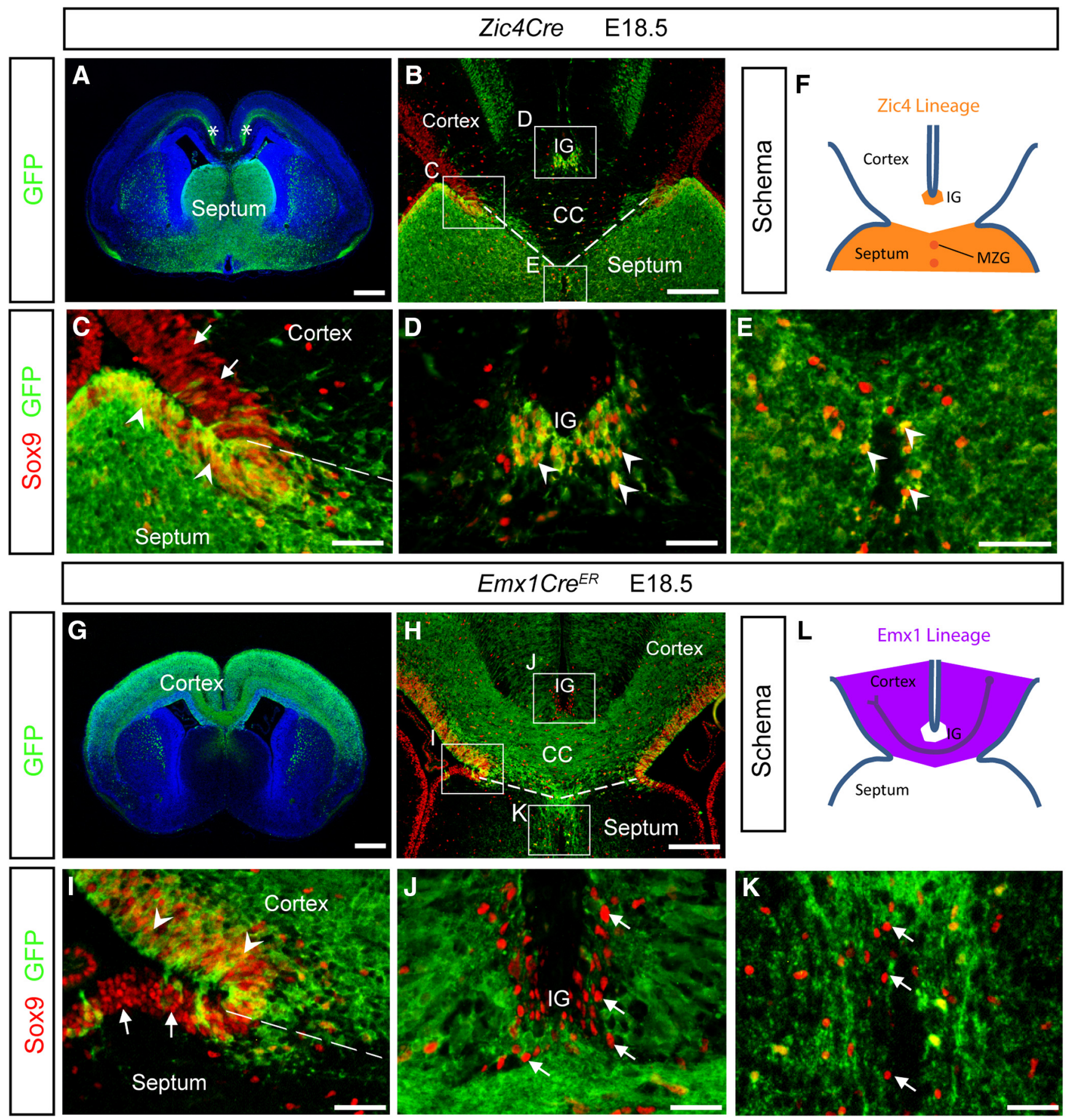

Figure 3. Emx1 and Zic4 lineage contribution at the CSB. A, Zic4 ${ }^{\text {cre }}$ allele combined with a lox-stop GFP reporter has been used to label cell populations at E18.5. Zic4 ${ }^{\text {cre }}$ labels cells of the septum (asterisks in $3 \boldsymbol{A}$ mark GFP in cortex). $\boldsymbol{B}-\boldsymbol{E}, Z_{i}{ }_{4}{ }^{\text {cre }}$ labels cells ventral to the CSB (dashed line, $\boldsymbol{B}, \boldsymbol{C}$ ) including Sox9 expressing cells (arrowheads, $\boldsymbol{C}$ ), but is not expressed by Sox9 expressing cells dorsal to the CSB (arrows, $\boldsymbol{C}$. Zic4 ${ }^{\text {cre }}$ is expressed by IG glial cells (arrowheads, $\boldsymbol{D}$ ) but not by surrounding cells. Zic4 ${ }^{\text {cre }}$ is expressed by MZ glial cells (arrowheads, $\boldsymbol{E}$ ). $\boldsymbol{F}$, Schematic of the Zic4 ${ }^{\text {cre }}$ expressing cell lineage. $\boldsymbol{G}, E m \times 1^{\text {creeR }}$ allele combined with a lox-stop GFP reporter has been used to label cell populations at E18.5. Emx ${ }^{\text {creeR }}$ labels cells of the cortex. $\boldsymbol{H}-\boldsymbol{K}, E m \times{ }^{\text {creeR }}$ labels cells dorsal to the CSB (dashed line, $\boldsymbol{H}, \boldsymbol{I}$ ) including Sox9 expressing cells (arrowheads, I), but is not expressed by Sox9-expressing cells ventral to the CSB (arrows, I). Emx ${ }^{\text {creeR }}$ is not expressed by IG glial cells (arrows,

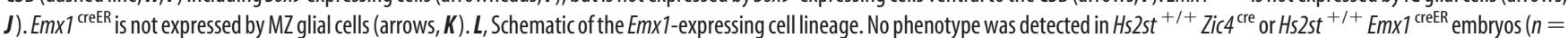
5 for each genotype). $\boldsymbol{C}-\boldsymbol{E}$ are higher-magnification images of the indicated regions in $\boldsymbol{B}$. I-Kare higher-magnification images of the indicated regions in $\boldsymbol{H}$. Scale bars: $\boldsymbol{A}, \boldsymbol{G}, 500 \mu \mathrm{m} ; \boldsymbol{B}, \boldsymbol{H}, 200 \mu \mathrm{m}$; $C-E$ and $I-K, 50 \mu \mathrm{m}$.

astroglial cells are present in the IG (Fig. 4E) and at the GW (Fig. $4 H$ ) in a pattern grossly similar to that of controls (cf. Fig. $4 D, G$ and $E, H)$. In Zic4 conditional mutants $\left(Z_{i c 4^{\mathrm{Cre}}}, \mathrm{Ext1}^{\mathrm{F} / \mathrm{FI}}\right)$, CC axons approach the midline but fail to cross (Fig. $4 C$, with higher magnification of IG and GW in F,I). Astroglial populations in Zic4 conditional mutants are obviously disrupted, with less in- tense GFAP staining at the midline (cf. IG region in Fig. 4D,F) and more GFAP at the GW than in controls (arrows in Fig. 4I; cf. Fig. 4G,I), suggesting that, in these embryos, astroglial precursors translocate less efficiently to the IG and instead remain in the GW. The cerebral cortex of $\mathrm{Zic}^{\mathrm{Cre}} ; \mathrm{Ext1}^{\mathrm{F} / \mathrm{Fl}}$ brains was thinned and the ventricles were enlarged (cf. Fig. $4 A, C$ ) and this 


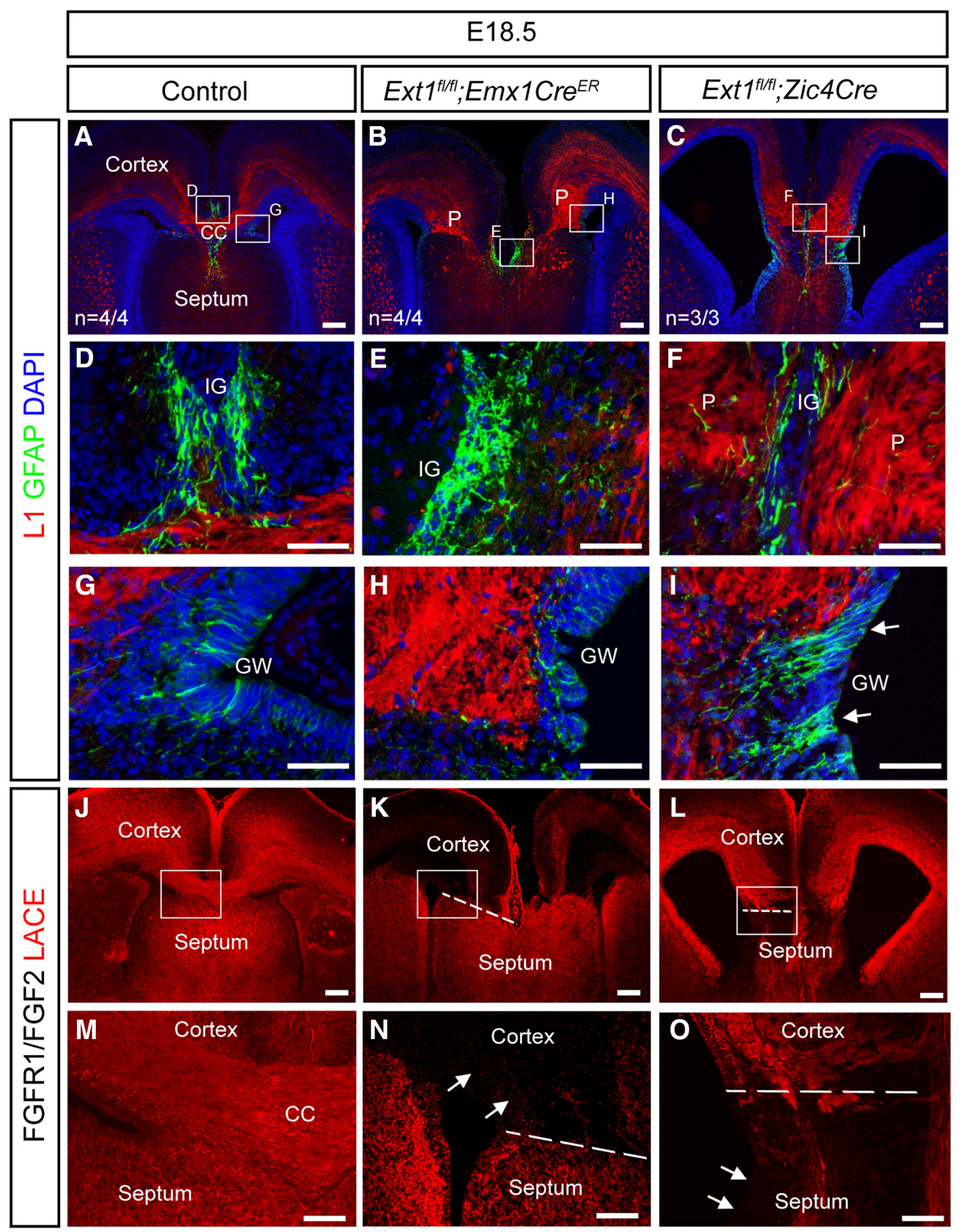

Figure 4. HS expression is required within both Emx 1 and Zic4-lineage cells for CC formation. $\boldsymbol{A}-\boldsymbol{I}$, Immunofluorescence for L1 (red) at E18.5 labels the CC, whereas GFAP (green) labels glia. In

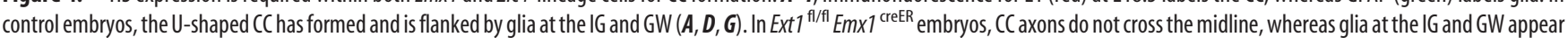

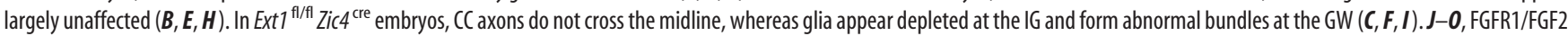
LACE assay is used to detect the presence of HS. In control embryos, the LACE signal can be seen throughout the telencephalon and is of similar intensity within both the cortex and the septum $(\boldsymbol{J}$,

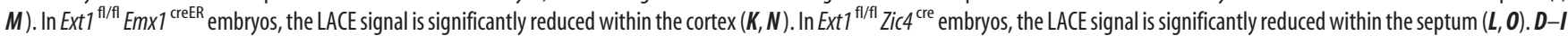
are higher-magnification images of the indicated boxed regions in $\boldsymbol{A}-\boldsymbol{C} . \boldsymbol{M}-\mathbf{0}$ are higher-magnification images of the boxed region in $\boldsymbol{J}-\boldsymbol{L}$, respectively. $\mathbf{S c a l e}$ bars: $\boldsymbol{A}-\boldsymbol{C}, \mathbf{G}-\boldsymbol{I}, 200 \mu \mathrm{m} ; \mathbf{D}-\boldsymbol{F}$ and $\boldsymbol{J}-\boldsymbol{L}, 100 \mu \mathrm{m}$.

hydrocephalus-like phenotype is intriguing because the cerebral cortex is not of the Zic4 lineage, indicating a non-cellautonomous mechanism by which HS regulates cerebral cortex development. The FGFR1/FGF2 LACE assay detects endogenous HS on tissue sections by forming ternary complexes with exogenously added FGF2 and FGFR1 (red LACE signal in Fig. 4J-O)
(Allen et al., 2001; Chan et al., 2015). HS is ubiquitously expressed in both cortical and septal compartments of control telencephalon (Fig. 4J, higher magnification of CSB in $M$ ) and, as intended, HS synthesis is blocked in the cortex and cortical axons of Emx1 ${ }^{\mathrm{CreER}} ; E x t 1^{\mathrm{Fl} / \mathrm{Fl}}$ embryos (Fig. $4 \mathrm{~K}$, CSB shown at higher magnification in $N$, with arrows indicating HS-deficient cortical 


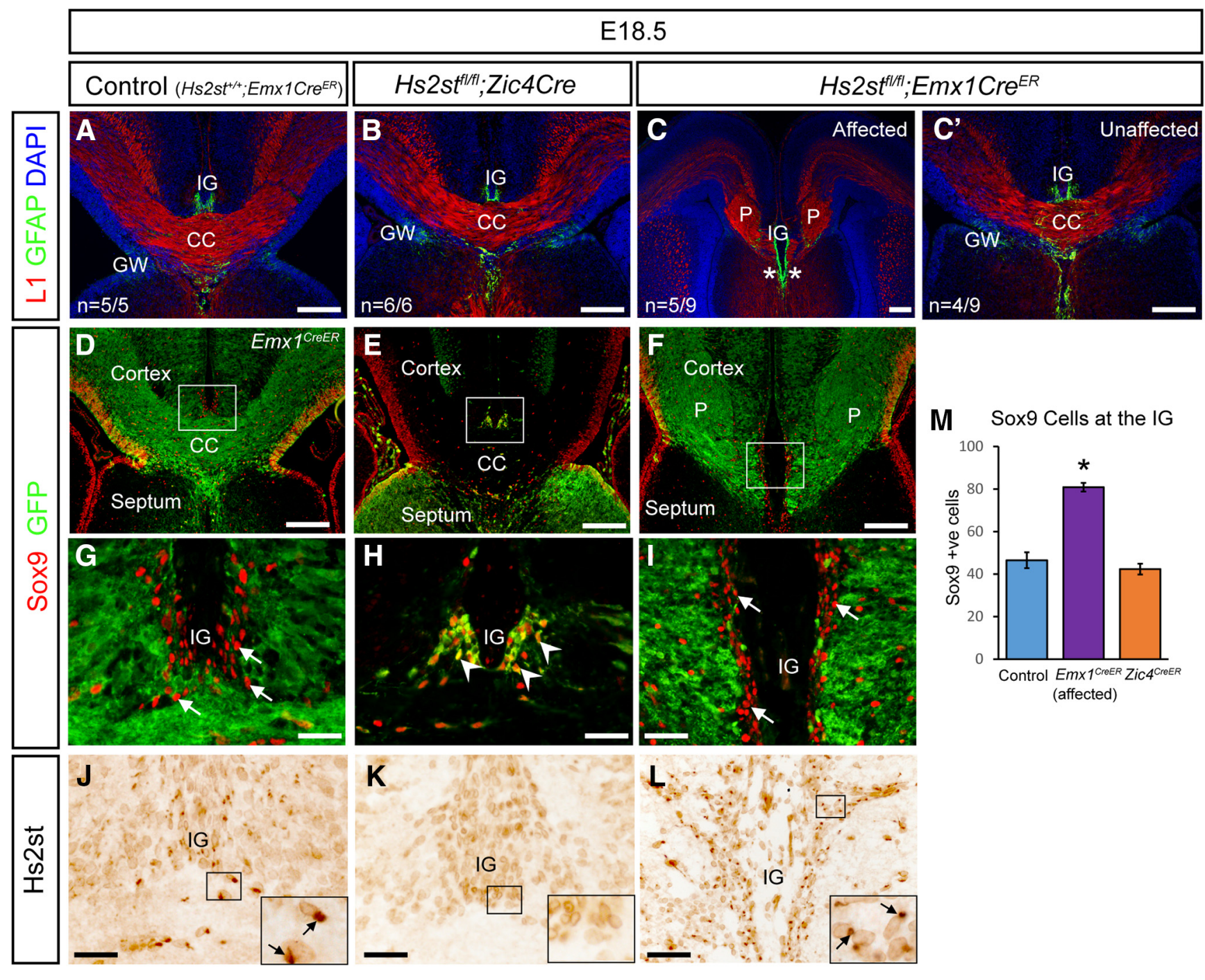

Figure 5. Hs2st expression is required within Emx1-lineage cells but notZic4-lineage cells for CC formation. $\boldsymbol{A}$-C, Immunofluorescence for L1 and GFAP at E18.5. In control embryos, the U-shaped

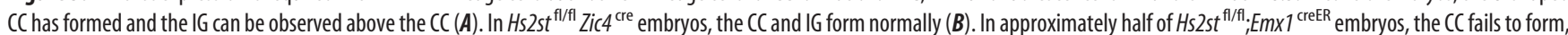

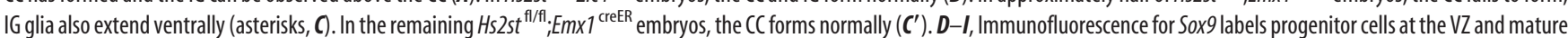

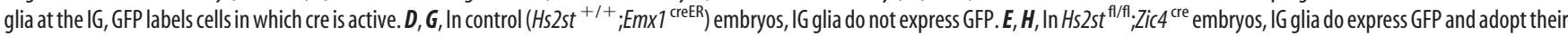

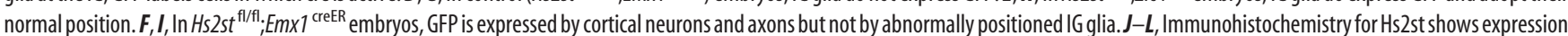

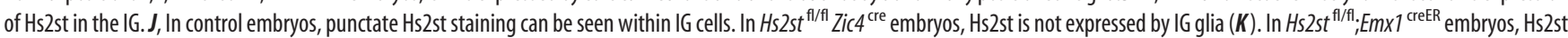
is expressed by displaced glial cells $(\boldsymbol{L})$. Hs2st immunohistochemistry in $\boldsymbol{J}-\boldsymbol{L}$ was performed on adjacent tissue sections to those in $\boldsymbol{D}-\boldsymbol{I}$. $\boldsymbol{M}$, Quantification of Sox9 expressing cell number at the $\mathbf{I}$ in

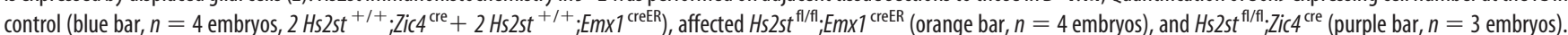

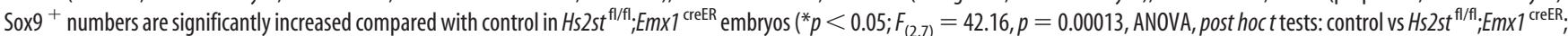
$t_{(4)}=-8.08, p=0.0013, t$ test; and control vs $H_{s} 2 s t^{f / f f} ; Z i c 4^{\text {cre }} ; t_{(5)}=0.92, p=0.40, t$ test). $\mathbf{G}-\boldsymbol{I}$ are higher-magnification images of boxed regions in $\boldsymbol{D}-\boldsymbol{F}$, respectively. Insets in $\boldsymbol{J}-\boldsymbol{L}$ are higher-magnification images of boxed region shown on each image. Scale bars: $\boldsymbol{A}-\boldsymbol{F}, 200 \mu \mathrm{m} ; \boldsymbol{G}-\boldsymbol{L}, 50 \mu \mathrm{m}$.

region) and in the septum of $Z i c 4^{\mathrm{Cre}} ; E x t 1^{\mathrm{F} / \mathrm{Fl}}$ embryos (Fig. $4 L$, higher magnification of CSB in $O$, with arrows indicating HSdeficient septum). Predigesting tissue sections with heparitinase eliminated the LACE signal (data not shown), confirming the specificity of this assay for detecting HS. The salient conclusions from the Ext1 conditional mutagenesis for the current study are that HS is indispensable from both the Zic4 and the Emx1 lineages for CC development and that removing HS from the Zic4 lineage inhibits Zic4 lineage astroglia from reaching the IG region.

$H s 2 s t$ is required by Emx1-lineage but not Zic4-lineage cells for CC development

Having established that both Zic4 and Emxl lineages need to synthesize HS for normal CC development, we next investigated whether 2-O HS sulfation of the HS is required in either lineage. Hs2st is the sole enzyme capable of imparting 2-O HS sulfation onto HS, so to determine the cellular requirement for 2-O HS sulfation, we deleted Hs2st in the Zic4 or Emxl lineages. Control $\mathrm{Hs} 2 \mathrm{st}^{+/+}$genotypes $\left(\mathrm{Hs}_{\mathrm{s}} \mathrm{st}^{+/+} ; \mathrm{Em} \times \mathrm{I}^{\mathrm{CreER}}\right.$ and $\left.\mathrm{H}_{s} 2 \mathrm{st}{ }^{+/+} ; \mathrm{Zic4}{ }^{\mathrm{Cre}}\right)$ displayed neither $\mathrm{CC}$ agenesis nor midline astroglial disorganization; the control embryo shown in Figure $5(A, D, G, J ; D$ and $G$ are reproduced from Fig. $3 \mathrm{H}, \mathrm{J})$ is of the $H s 2 s t^{+/+}$;Em $x 1^{\mathrm{CreER}}$ genotype. The $\mathrm{CC}$ and the midline astroglial structures form normally in $H_{s} 2 s t^{\mathrm{f} / \mathrm{fl}} ; \mathrm{Zic} 4^{\mathrm{Cre}}$ conditional mutants and the organization of $\mathrm{L}^{+}$axons and $\mathrm{GFAP}^{+}$astroglia are indistinguishable from control embryos (6/6 embryos) (cf. Fig. 5B,A). The organization of $\mathrm{GFP}^{+}$Zic4-lineage cells is the same in $H s 2 s t^{\mathrm{fl} / \mathrm{fl}} ; \mathrm{Zic} 4^{\text {Cre }}$ embryos as in $H s 2 s t^{+/+} ; Z_{i c 4}{ }^{\text {Cre }}$ embryos (cf. Figs. $5 E, H$ and $3 B, D$ ) and IG 
Sox $9^{+}$cell counts confirm that the numbers of Sox $9^{+}$cells in the IG are not significantly different from control $\mathrm{Hs} 2 \mathrm{st}{ }^{+/+}$embryos (Fig. 5M, cf. blue and orange bars), indicating no cellautonomous requirement for Hs2st in the Zic4-lineage Sox $9^{+}$IG astroglia. To exclude the possibility of a compensatory mechanism by which the $H s 2 s t^{\mathrm{fl} / / \mathrm{l}}$; $\mathrm{Zic} 4^{\mathrm{Cre}} \mathrm{IG}$ is populated by $H s 2 s t^{+/+}$ cells from a different lineage, we performed Hs2st immunohistochemistry and confirmed that Hs2st expression is indeed absent from all cells in the IG (Fig. $5 K$, note this is an adjacent section from the same embryo to the one shown in $H$ ). In $H s 2 s t^{\mathrm{fl} / \mathrm{fl}}$; $E m \times 1^{\text {CreER }}$ embryos, the CC fails to form in $\sim 50 \%$ of cases and embryos either had a severe phenotype (Fig. 5C, 5/9 embryos) or appeared completely unaffected (Fig. 5C', 4/9 embryos). CC axons form Probst bundles on either side of the telencephalic midline, and the $\mathrm{GFAP}^{+}$IG is expanded (asterisks in Fig. $5 \mathrm{C}$ ). The anatomy and incomplete penetrance of the CC phenotype in $H s 2 s t^{\mathrm{fl} / \mathrm{fl}} ; E m \times 1^{\mathrm{CreER}}$ embryos closely resemble constitutive null $H s 2 s t^{-I-}$ embryos, indicating that Hs2st function within the Emx1 lineage is sufficient for normal CC development (Conway et al., 2011; Clegg et al., 2014). As in control Hs2st ${ }^{+/+} ; E m \times 1{ }^{\text {CreER }}$ embryos (Fig. $5 D, G$ ), the GFP and Sox 9 signals did not overlap in the IG region of control or $H s 2 s t^{\mathrm{fl} / \mathrm{fl}} ; E m \times 1^{\mathrm{CreER}}$ embryos (Fig. $5 F$, boxed area shown at higher magnification in $I$ ) and the Sox $9^{+}$ cells in the IG of control embryos and the expanded IG of $H s 2 s t^{\mathrm{fl} / \mathrm{fl}}$; Emx $1^{\text {CreER }}$ embryos were $\mathrm{GFP}^{-}$(arrows in Fig. 5I indicate Sox $9^{+}$;GFP ${ }^{-}$cells). Counts of Sox $9^{+}$cells confirmed a significant increase in the IG of affected $H s 2 s t^{\mathrm{fl} / \mathrm{fl}} ; E m \times 1^{\text {CreER }}$ embryos compared with controls (Fig. $5 M$, cf. blue and purple bars). Immunostaining for Hs2st on adjacent sections confirmed that IG cells in $H s 2 s t^{\mathrm{fl} / f \mathrm{l}} ; E m x 1^{\text {CreER }}$ embryos retain Hs2st protein expression (Fig. $5 L$ ). Because Sox ${ }^{+}$IG astroglia do not belong to the Emxl lineage, their ectopic position in $H s 2 s t^{\mathrm{fl} / \mathrm{fl}} ; E m \times 1^{\mathrm{CreER}} \mathrm{em}-$ bryos despite retaining $H s 2 s t$ function allows us to conclude a non-cell-autonomous requirement for Hs2st in the translocation of astroglial precursors to the IG.

The salient conclusions from these conditional mutagenesis experiments are that, although the Zic4-lineage astroglia do require Ext1 to form midline astroglial structures, they do not require Hs2st, strongly suggesting that, whereas these Zic4-lineage cells require $\mathrm{HS}$ on their cell surface to respond to translocation signals, there is no need for the HS to be 2-O sulfated. In contrast, $H s 2 s t$ is absolutely required in the surrounding Emx1-lineage cells, indicating a non-cell-autonomous mechanism by which 2-O HS sulfation controls the transmission of translocation signals to the Zic4-lineage astroglial precursors.

\section{Hs2st is not required cell autonomously by CC axons to navigate the midline}

The conditional mutagenesis experiments showed that Hs2st has a non-cell-autonomous role in $\mathrm{GW} \rightarrow \mathrm{IG}$ somal translocation, but because Hs2st is expressed throughout the cerebral cortex, did not resolve whether there is an additional cell autonomous requirement in CC axon navigation. To solve this, we performed ex vivo transplantation experiments in which cerebral cortical tissue from transgenic mice ubiquitously expressing $\tau$ GFP, which efficiently labels axons of $\tau \mathrm{GFP}^{+}$cells, was transplanted into $\tau \mathrm{GFP}^{-}$telencephalic slices containing the CC axon pathway and CSB structures (Pratt et al., 2000; Niquille et al., 2009). When WT E17.5 $\mathrm{GFP}^{+}$cortical explants are transplanted into age-matched $\tau \mathrm{GFP}^{-}$WT cortical slices, $\mathrm{TGFP}^{+}$axons extend across the telencephalic midline, forming the characteristic $\mathrm{U}$ shape of the $\mathrm{CC}$ and reaching the cortex of the opposite hemisphere $(n=3 / 3$ cultures, arrows in Fig. $6 A, D$ point to crossing axons). When $H s 2 s t^{-1-} \tau \mathrm{GFP}^{+}$cortical explants are transplanted into $\tau \mathrm{GFP}^{-} \mathrm{WT}$ slices, axons are able to cross the midline to reach the opposite hemisphere in a manner indistinguishable from that seen in the WT $\rightarrow$ WT transplants $(n=4 / 4$ cultures, arrows in Fig. $6 B, E$ point to crossing axons). In contrast, when $\tau \mathrm{GFP}^{+} \mathrm{WT}$ cortical explants are transplanted into $\mathrm{GFP}^{-}$ $H s 2 s t^{-1-}$ slices, axons are unable to reach the opposite cortical hemisphere and instead remain within the cingulate cortex or invade the septum ( $n=6 / 6$ cultures, Fig. $6 C, F$, arrowheads point to axons growing into the septum), resembling the in vivo CC phenotype observed in Hs2st ${ }^{-1-}$ embryos (Conway et al., 2011; Clegg et al., 2014). In all cultures, a few axons grew into the septum (arrowheads in Fig. $6 D-F)$. Schematics summarizing these experiments are shown in Figure 6, G-I. These data show that 2-O HS sulfation is not required cell autonomously by $\mathrm{CC}$ projection neurons for axon guidance across the midline, strongly suggesting that disorganization of midline guidepost astroglial cells is the primary cause of the $H s 2 s t^{-1-} \mathrm{CC}$ agenesis phenotype.

\section{Abnormally high FGF/ERK signaling causes the $\mathrm{Hs} 2 \mathrm{st} \mathrm{T}^{-/-}$ precocious astroglial translocation phenotype}

We previously reported a correlation between hyperactive ERK signaling at the CSB and precocious somal translocation of astroglia to the midline in $H s 2 s t^{-1}$ embryos, but we did not formally establish that this stemmed from hyperactive FGF/ERK signaling (Clegg et al., 2014; Chan et al., 2017). To address this, we used an ex vivo assay in which coronal WT or $H s 2 s t^{-1-}$ telencephalic slices incorporating the CSB were cultured on floating membranes for long enough to allow somal translocation to the midline and attempted to rescue the $H s 2 s t^{-1-}$ phenotype by pharmacological abrogation of FGF/ERK signaling. WT or $H s 2 s t^{-1-}$ E14.5 slices were cultured in the presence of the Fgfr1 inhibitor SU5402 dissolved in DMSO (FGFi treatment) to inhibit FGF/ERK signaling or in DMSO alone (untreated control) for $48 \mathrm{~h}$ (Fig. 7A). To aid subsequent identification of translocating cells, a subpopulation RGCs undergoing S-phase in the VZ at E14.5 were labeled just before culturing with a single pulse of BrdU. Immunohistochemistry for pErk (brown stain in Fig. $7 B, D, F, H)$ confirms inhibition of FGF/ERK signaling in both FGFi treated WT and $H s 2 s t^{-1-}$ cultures (Fig. $7 D, H$ ) compared with untreated cultures (Fig. $7 B, F$ ), showing that FGF signaling through Fgfrl accounts for ERK phosphorylation in both genotypes. This demonstrates that ERK hyperactivation in $\mathrm{Hs}_{\mathrm{s}} \mathrm{st} \mathrm{I}^{-1-}$ embryos does not stem from an FGF-independent mechanism for ERK activation (Clegg et al., 2014; Chan et al., 2017). After $48 \mathrm{~h}$, some Sox ${ }^{+}$cells (red) had left the VZ and translocated to the midline in untreated WT cultures (arrow in Fig. $7 C$ ), with many more populating the midline in untreated $\mathrm{Hs}_{2} \mathrm{st}{ }^{-1-} \mathrm{cul}-$ tures (arrow in Fig. 7G), validating that our ex vivo assay replicates the in vivo Hs2st ${ }^{-1-}$ phenotype. Consistent with our hypothesis, FGFi treatment of both WT and $H s 2 s t^{-1-}$ cultures resulted in a large decrease in Sox ${ }^{+}$cells reaching the midline (cf. Fig. $7 E, I$ and $C, G$ ). We quantified glial translocation by counting the numbers of Sox $9^{+}$cells born in the VZ at E14.5 $\left(\right.$ Sox $9^{+}$;BrdU ${ }^{+}$cells, yellow; inset in Fig. 7C, E, G,I shows higher magnification) that had exited the $\mathrm{VZ}$ toward the midline (VZ demarcated by dotted line in Fig. 7C, E, G,I) after $2 \mathrm{~d}$ in culture. Counts of $\mathrm{BrdU}^{+}$; $\mathrm{Sox} 9^{+}$cells showed that glial translocation was significantly greater in $H s 2 s t^{-1-}$ compared with WT cultures along the rostrocaudal axis (dark purple and green lines in Fig. $7 \mathrm{~J}$ ) and in both cases was almost completely suppressed by FGFi treatment (pale purple and green lines in Fig. $7 J$ ).

We conclude that the precocious glial translocation phenotype in $\mathrm{H} s 2 s t^{-1-}$ embryos is caused by hyperactive FGF/ERK 

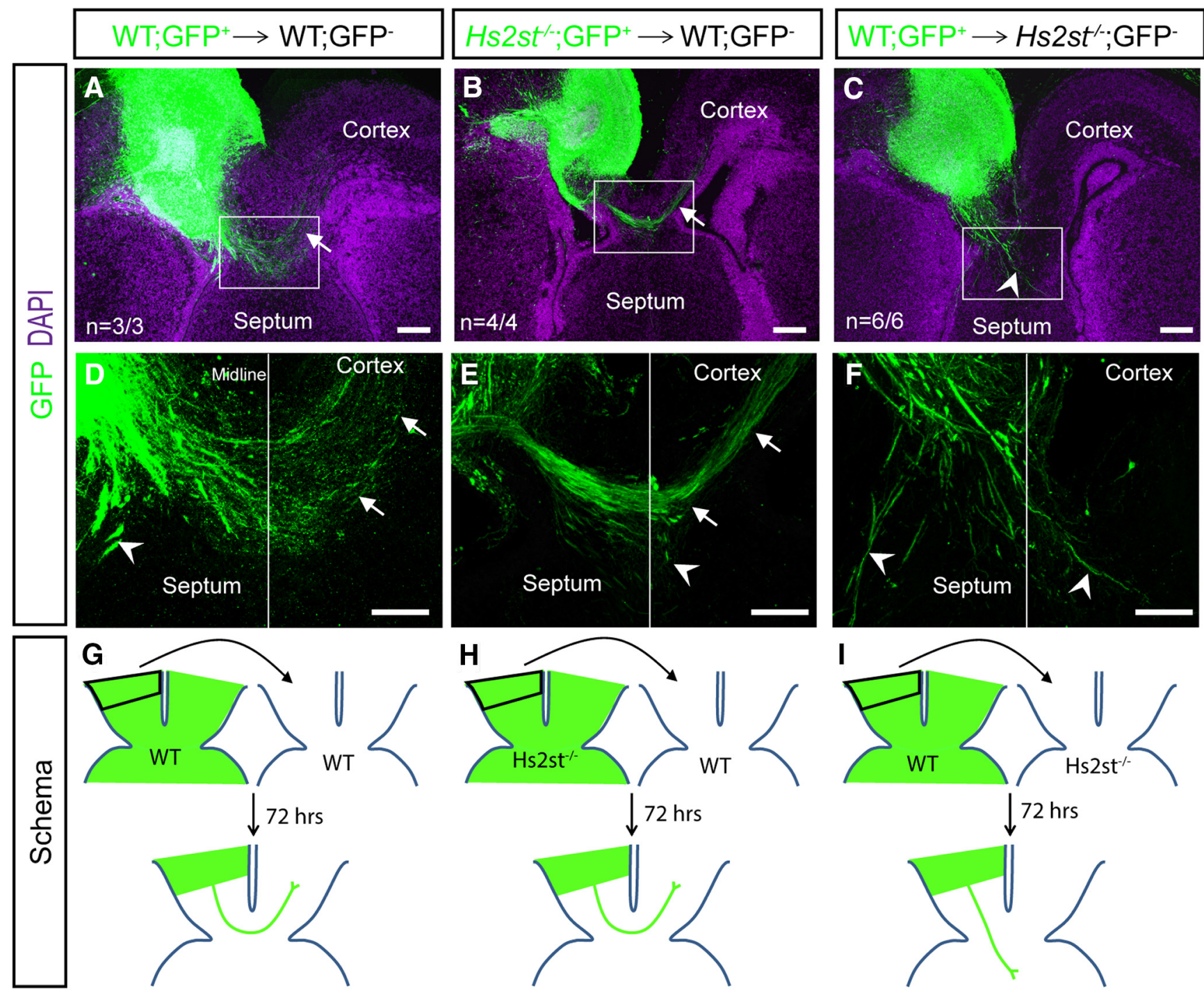

Figure 6. Hs2st is not required by $C\left(C\right.$ axons to cross the telencephalic midline. $A, D$, After homotypic transplantation of E17.5 cortical explants from GFP ${ }^{+}$control tissue into the cortex of GFP control brain slices, $\mathrm{GFP}^{+} \mathrm{CC}$ axons are able to project across the midline (arrows, D). B, E, After transplantation of GFP ${ }^{+} \mathrm{Hs}_{2} \mathrm{st}^{-1}{ }^{-}$cortical explants into GFP ${ }^{-}$control brain slices, GFP ${ }^{+} \mathrm{CC}$ axons are able to project across the midline (arrows, E). $\boldsymbol{C}, \boldsymbol{F}$, After transplantation of cortical explants from GFP ${ }^{+}$control tissue into the cortex of GFP ${ }^{-} \mathrm{Hs}_{\mathrm{s}} \mathrm{st}^{-1-}$ brain slices, GFP ${ }^{+} \boldsymbol{C}$ axons are unable to project across the midline and invade the septum. Arrowheads indicate axons navigating into the septum in all conditions. $\mathbf{G}-\boldsymbol{I}, \mathbf{S}$ chematic of transplant experiments shown in $\boldsymbol{A}-\boldsymbol{C}$. $\boldsymbol{D}-\boldsymbol{F}$ are higher-magnification images of the boxed region in $\mathbf{A}-\boldsymbol{C}$, respectively. Scale bars, $200 \mu \mathrm{m}$ in all panels.

signaling from E14.5 on. Together with our Hs2st conditional mutagenesis experiments demonstrating a non-cell-autonomous role for Hs2st in astroglial precursor translocation, we hypothesize that Hs2st normally suppresses the supply of FGF proteins to translocation competent astroglial precursors in the GW.

\section{Hs2st suppresses Fgf17 protein levels}

We next sought to identify an FGF protein that is targeted by Hs2st. Despite its well known role in CC development, Fgf8 protein levels are not significantly increased at the CSB of $\mathrm{Hs}_{\mathrm{s}} \mathrm{st}^{-1-}$ embryos, forcing us to consider other FGFs (Clegg et al., 2014; Chan et al., 2017). A promising candidate is Fgf17, a member of the Fgf8 subfamily transcribed at the CSB in a similar pattern to Fgf8 (Cholfin and Rubenstein, 2008; Zhang X et al., 2012). Fgf17 is a canonical FGF that binds to HS, so it is potentially regulated via its interaction with HS and is known to play a role in patterning the telencephalon, although its role in CC development has not been fully characterized (Cholfin and Rubenstein, 2007; Hoch et al., 2015; Li and Kusche-Gullberg, 2016). We hypothe- sized that Hs2st normally suppresses Fgf17 protein and predicted that Fgf17 protein levels would be increased at the $H s 2 s t^{-1-}$ CSB. We compared the expression of Fgf17 protein in the developing CSB of WT and Hs2st ${ }^{-1-}$ embryos at three developmental stages, E12.5, E14.5, and E16.5, spanning the interval of midline glial translocation. At E12.5, telencephalic Fgf17 protein is restricted to the CSB region with no obvious difference between WT and $H s 2 s t^{-1-}$ (cf. Fig. 8A1,B1 and A2,B2). By E14.5, there is an expanded Fgf17 protein domain at the CSB of $H s 2 s t^{-1-}$ embryos (cf. Fig. $8 D 1, E 1$ and $D 2, E 2 ;{ }^{\star} E 2$ marks the expanded Fgf17 protein domain). Quantification of Fgf17 immunofluorescence shows a significant $\sim 2$-fold increase in Fgf17 protein levels in this region of $H s 2 s t^{-1-} \mathrm{CSB}$ (Fig. $8 \mathrm{~W}$, cf. blue and green bars). At E16.5, Fgf17 protein is much closer to detection threshold than at the earlier stages in both genotypes (Fig. 8G1,G2,H1,H2) although the increased protein spread in the mutant persists ${ }^{*}$ in Fig. $8 \mathrm{H} 2$ ), indicating that the Hs2st ${ }^{-1-} \mathrm{CSB}$ is exposed to a prolonged overdose of Fgf17 protein spanning E14.5-E16.5. We next examined Fgfl7 mRNA at the CSB to determine whether the 
A

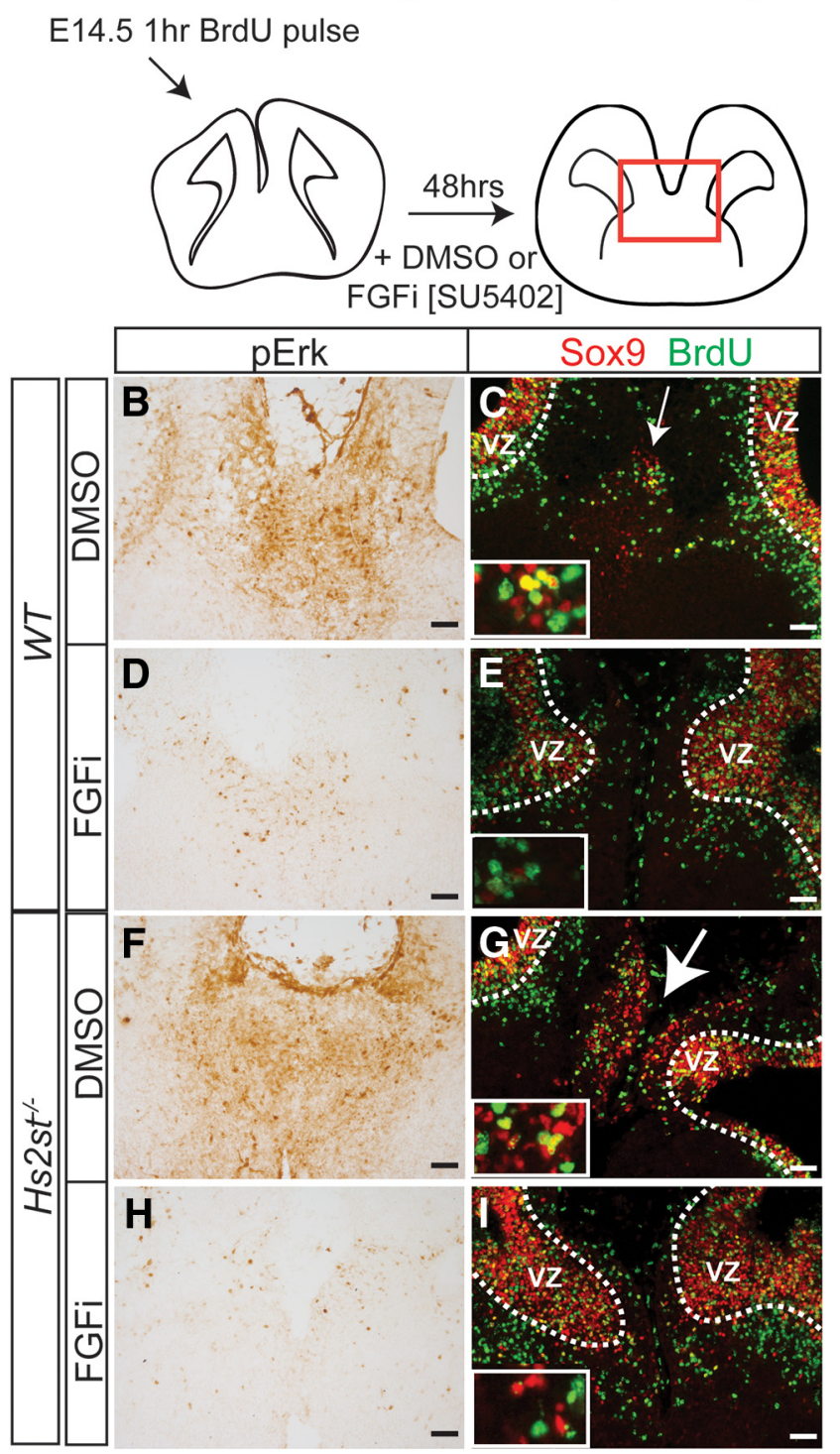

J

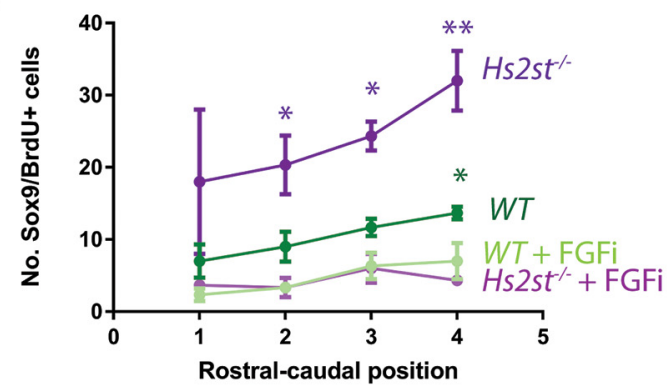

increase in Fgf17 protein in $H s 2 s t^{-1-}$ CSB was underpinned by altered $\mathrm{Fg} f 17$ gene expression. There was no evidence for this at E12.5 or E14.5, when the Fgf17 mRNA expression pattern remained similar between $H_{s} 2 s t^{+/+}$and $H s 2 s t^{-1-}$ embryos (cf. Fig. $8 C 1, C 2$ and $F 1, F 2$ ); however, the expression domain of $F g f 17$ mRNA is increased in E16.5 Hs2st ${ }^{-1-}$ CSB (cf. Fig. 8Iland I2, ${ }^{*}$ in I2 marks expanded Fgf17 mRNA domain). This subsequent increase in Fgf17 mRNA in the E16.5 Hs2st ${ }^{-1-}$ CSB indicates that the $H s 2 s t^{-1-}$ phenotype has a transcriptional component or that there are more cells expressing Fgf17 mRNA in the expanded $H s 2 s t^{-1-}$ IG, although this cannot be the primary event because it is not apparent at E14.5, the stage at which we previously showed that precocious astroglial precursor translocation was well under way in $H s 2 s t^{-1-}$ embryos (Clegg et al., 2014).

Mosaic analysis (Fig. 5) indicated that Hs2st function in the Emxl lineage negatively regulates a signal promoting $\mathrm{GW} \rightarrow \mathrm{IG}$ translocation of Zic4-lineage glial cells by a non-cell-autonomous mechanism and Fgf17 expression analysis (Fig. 8) makes Fgf17 a strong candidate for the signal. Based on this, we hypothesized that Fgf17 is expressed in cells surrounding the Zic4-lineage cells and performed detection of Fgf17 mRNA or protein in E14.5 WT embryos in which the Zic4 lineage is labeled $\mathrm{GFP}^{+}$. Fgf $17 \mathrm{mRNA}$ is expressed at the GW and the IG (Fig. $8 \mathrm{~J}$ ) and higher-power magnification shows that, in the $\mathrm{VZ}, \mathrm{GFP}^{+}$cells express little if any Fgf17 mRNA and, conversely, cells expressing the highest levels of $\mathrm{Fgfl} 17 \mathrm{mRNA}$ are $\mathrm{GFP}^{-}$(Fig. 8K1-K3, arrows indicate $\mathrm{GFP}^{+}$cell location). This complementarity between Fgf17 mRNA-expressing and Zic4-lineage cells is preserved at the IG (Fig. $8 L 1-L 3$, arrows indicate $\mathrm{GFP}^{+}$cell location). Fgf17 protein predominates at the IG (Fig. $8 M$ ) and higher-power magnification shows that, although Fgf17 protein is barely detectable at the GW (Fig. 8N1-N3), there are a number of much more highly Fgf17-expressing cells at the IG and these cells are $\mathrm{GFP}^{-}$, confirming that they do not belong to the Zic4 lineage (Fig. 8O1-O3, arrows indicate $\mathrm{GFP}^{+}$cell location). Interestingly, although cells in the GW and IG express comparable levels of Fgf17 mRNA (cf. Fig. $8 \mathrm{~K} 1, L 1)$, the expression of Fgf17 protein is much higher in the IG (cf. Fig. 8N1,O1), suggesting a posttranscriptional repression selectively at the GW. Our identification of $\mathrm{Hs} 2 \mathrm{st}$ as a repressor of Fgf17 protein levels at this stage makes Hs2st a strong candidate; indeed, closer examination of $H s 2 s t$ expression using the Hs2st-LacZ reporter shows that Hs2st is expressed in a $\mathrm{GW}^{\text {High }}$-IG ${ }^{\text {Low }}$ pattern (Fig. 8P, also apparent in the Hs2st immunohistochemistry; Fig. $1 B$ ) complementary to the $\mathrm{GW}^{\text {Low }}$ $\mathrm{IG}^{\text {High }}$ Fgf17 protein distribution. Together, these data bolster the idea that Hs2st acts to suppress Fgf17 protein supply to Zic4lineage cells via a posttranscriptional mechanism.

We conclude that Hs2st primarily suppresses the level and spread of Fgf17 protein emanating from the Emxl lineage in the CSB.
Figure 7. Hyperactive Fgf signaling causes precocious glia translocation in $\mathrm{Hs}_{\mathrm{s}} \mathrm{st}{ }^{-1-}$ CSB. $A$, Experimental outline of $\mathrm{Hs}_{\mathrm{s}} \mathrm{st}{ }^{-1-}$ phenotypic rescue experiment. Pregnant females were injected at E14.5 with a BrdU pulse and CSB slices collected after $1 \mathrm{~h}$ and cultured for $48 \mathrm{~h}$. $\boldsymbol{B}$-I, WT or $\mathrm{Hs}_{2} \mathrm{st}{ }^{-1-}$ CSB slices were cultured in the presence of either SU5402 (FGFi) or DMSO (untreated vehicle control). $\boldsymbol{B}, \boldsymbol{D}, \boldsymbol{F}, \boldsymbol{H}$, pErk immunohistochemistry showing that FGFi treatment reduces Fgf/ERK signaling. $(\boldsymbol{C}, \boldsymbol{E}, G, I)$ Immunofluorescence for BrdU and Sox9 in WT $(\boldsymbol{C}, \boldsymbol{E})$ and $H s 2 s t^{-I-}(\boldsymbol{G}, I)$ slices treated with FGFi $(\boldsymbol{E}, \boldsymbol{I})$ or untreated $(\boldsymbol{C}, \boldsymbol{G})$. Curved dotted line demarcates the basal edge of the $\mathrm{VZ}$, arrows in $\mathbf{C}$ and $\mathbf{G}$ point to accumulations of $\mathrm{BrdU} / \mathrm{Sox} 9^{+}$ cells at the midline (arrow size corresponds to cell number), with higher magnification insets showing Sox9/BrdU ${ }^{+}$(yellow) double-labeled cells in IG region. J, Quantification of Sox9/ $\mathrm{BrdU}^{+}$double-labeled cells in WT or Hs2st ${ }^{-1-}$ CSB slice cultures treated with FGFi or $\leftarrow$

untreated ( $n=3$ embryos for each condition). For both genotypes, FGFi treatment significantly reduced the number of Sox9/BrdU ${ }^{+}$cells that exit the VZ and moved toward the IG at one or more rostrocaudal position [significant differences due to FGFi treatment within each genotype indicated on graph as ${ }^{*} p<0.05,{ }^{* *} p<0.01 ; F_{(3,32)}=31.00, p=0.0000000014$, two-way ANOVA, followed by $t$ test with Sidak's correction for multiple comparisons at each positon along the rostrocaudal axis. WT FGFi vs WT untreated: position $1\left(t_{(16)}=1.67, p=0.24, t\right.$ test); position $2\left(t_{(16)}=2.37, p=0.11, t\right.$ test); position $3\left(t_{(16)}=2.25, p=0.15\right.$, $t$ test); and position $4\left(t_{(16)}=2.81, p=0.050, t\right.$ test). $\mathrm{Hs} 2 s t^{-1-}$ FGFivs $\mathrm{Hs}_{2} 2 \mathrm{st}{ }^{-1-}$ untreated: position $1\left(t_{(16)}=\right.$ $2.38, p=0.11, t$ test $)$; position $2\left(t_{(16)}=2.83, p=0.048, t\right.$ test $)$; position $3\left(t_{(16)}=3.05, p=\right.$ $0.030, t$ test); and position $4\left(t_{(16)}=4.60, p=0.0012, t\right.$ test]. Scale bars in $B-I, 100 \mu \mathrm{m}$. 




\begin{tabular}{|c|ccccc|}
\hline Zic4 ${ }^{\text {Cre }}$ & Fgf17 & GFP & Merge & Fgf17 & GFP \\
\hline \hline Midline & & GW & & Merge \\
\hline
\end{tabular}
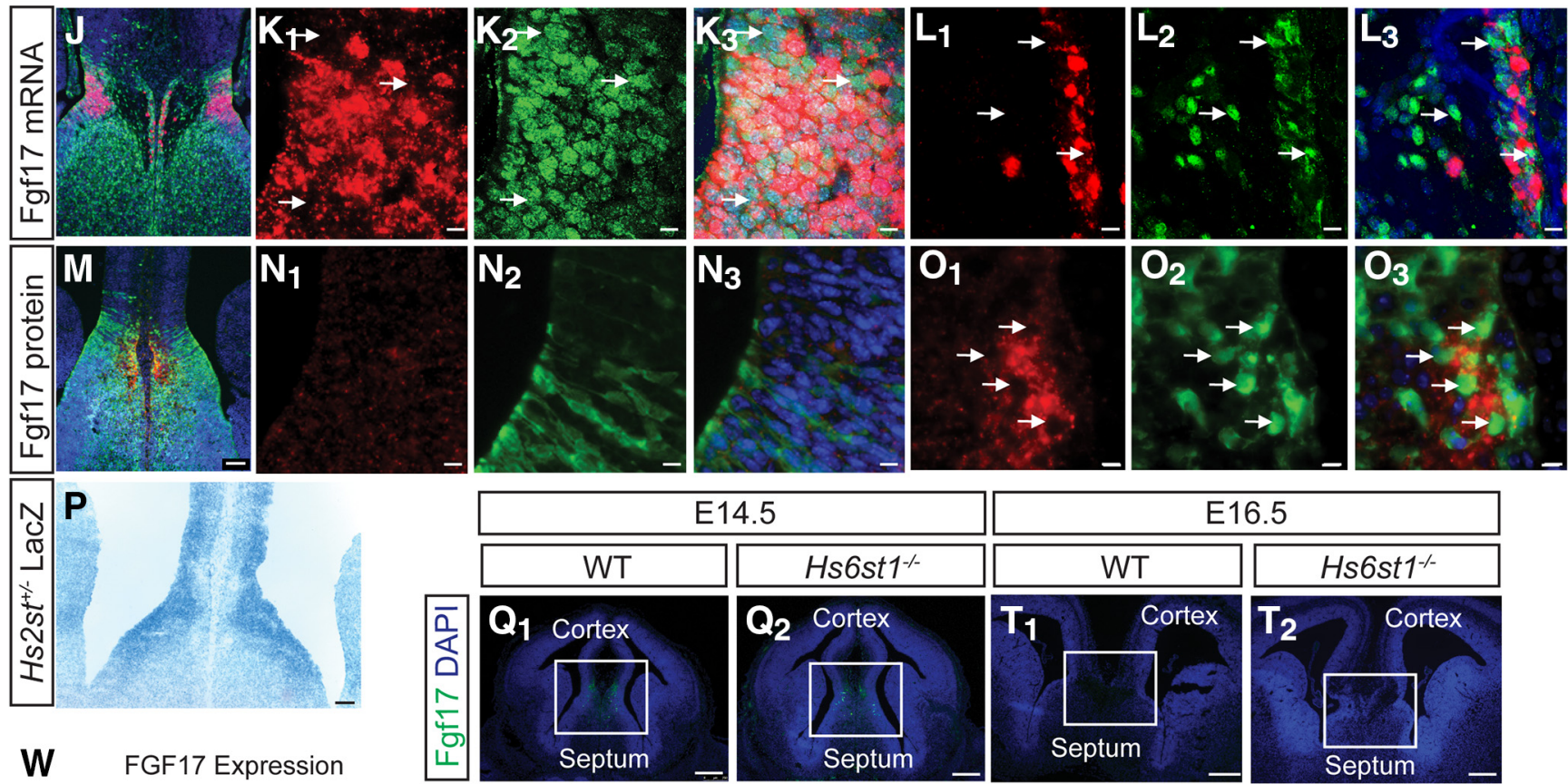

W FGF17 Expression
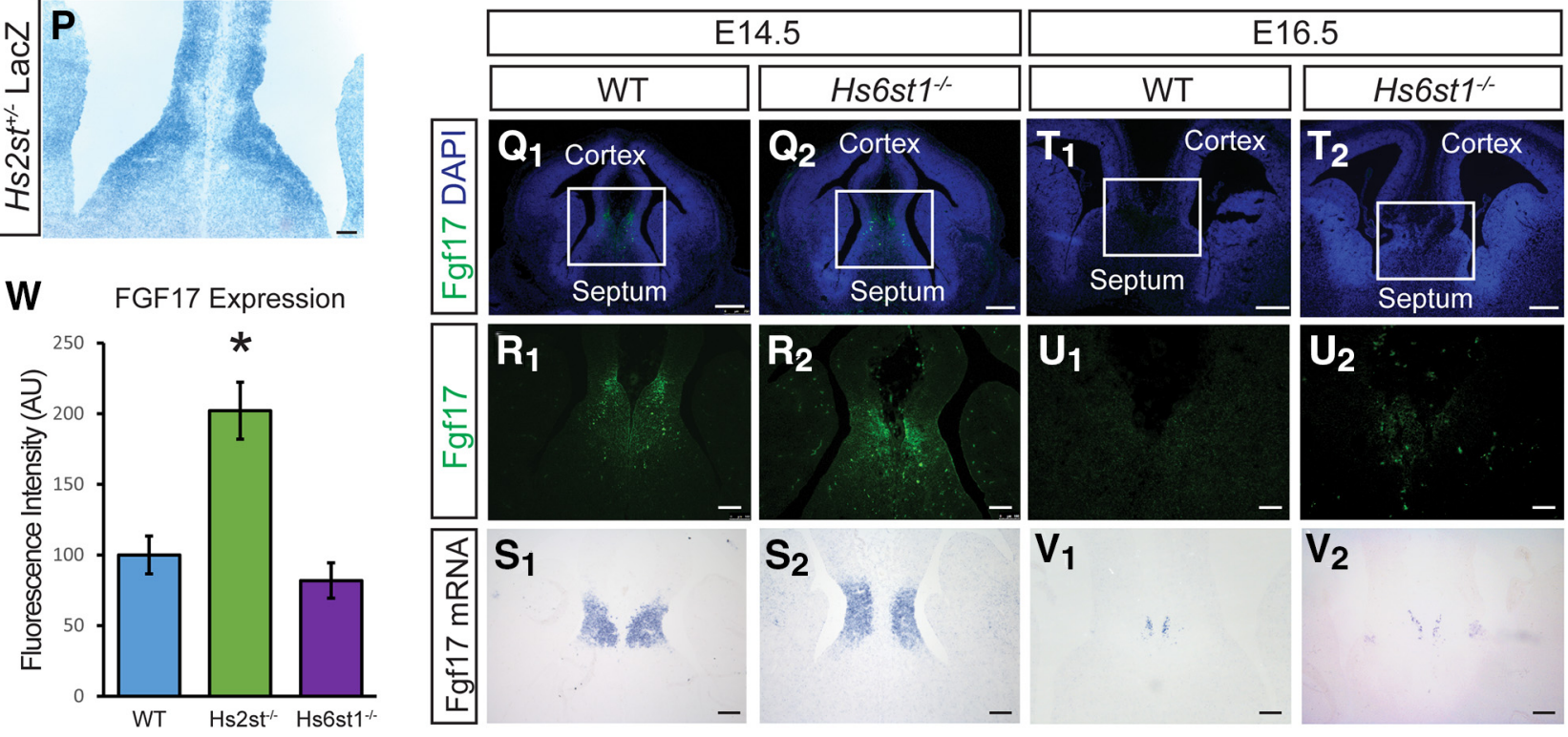

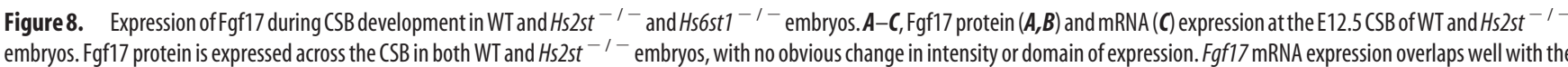

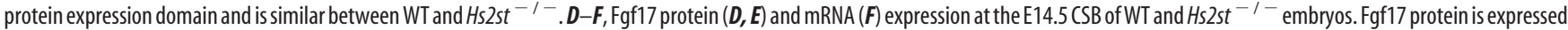
at low levels at the CSB of WT embryos. In Hs2st ${ }^{-1-}$ embryos, the protein expression domain expands across the CSB (asterisks in E2). Fgf17 mRNA is unchanged at the CSB between WT and Hs2st ${ }^{-1-}$ embryos. $\mathbf{G}-\boldsymbol{I}$, Fgf17 protein $(\boldsymbol{G}, \boldsymbol{H})$ and mRNA (I) expression at the E16.5 CSB of WT and Hs2st ${ }^{-1}$ embryos. Fgf17 protein is expressed at low levels at the CSB of WT embryos (H1). In $\mathrm{Hs}_{\mathrm{S} 2 \mathrm{~S}^{-1-}}{ }^{-}$embryos, the protein expression domain expands (asterisks, H2). There is a concurrent increase in Fgf17 mRNA (asterisk, I2). J-0, Fgf17 mRNA (Figure legend continues.) 


\section{Hs6st1 does not affect Fgf17 protein levels}

We next addressed whether the ability of 2-O HS sulfation to suppress Fgf17 protein levels in vivo represented a specific function of Hs2st or was redundant with other HSTs. We chose to examine Hs6st1, an HST that catalyzes 6-O HS sulfation, because we have previously shown that Hs6st1 (but not Hs2st) suppresses levels of the closely related Fgf8 protein at the CSB in vivo (Clegg et al., 2014; Chan et al., 2017). However, we were unable to detect increased expression of Fgf17 protein (cf. Fig. 8Q1,R1 and Q2,R2 and $T 1, U 1$ and $T 2, U 2$ ) or Fgf17 mRNA (cf. Fig. 8S1,S2 and $V 1, V 2)$ in Hs6st1 ${ }^{-1-}$ compared with WT CSB at either E14.5 or E16.5. Quantification of Fgf17 immunofluorescence shows unchanged Fgf17 protein levels in this region of Hs6st1 ${ }^{-1}$ CSB (Fig. $8 \mathrm{~W}$, cf. blue and purple bars). These data demonstrate that the negative relationship between $H s 2 s t$ and $F g f 17$ is selective in vivo because it does not apply to Hs6st1.

\section{Exogenously applied Fgf17 phenocopies the Hs2st ${ }^{-/-}$ astroglial translocation phenotype}

Our data suggest that the Hs2st ${ }^{-/-}$phenotype stems from abnormally high levels of Fgf17 protein at the CSB, causing FGF/ ERK hyperactivation and precocious somal translocation to the IG. This requires that $H s 2 s t^{-1-}$ CSB cells are competent to respond to Fgf17 protein and that application of ectopic Fgf17 triggers precocious glial translocation, neither of which has been previously established. We redeployed the CSB ex vivo culture assay (Fig. 7) with the modification that beads soaked in either recombinant Fgf17 protein (Fgf17 treatment) or in BSA (control) were implanted into coronal slices of CSB region on either side of the midline (Fig. 9A). WT or Hs2st ${ }^{-1-}$ slices implanted with Fgf17 and BSA beads were cultured for $2 \mathrm{~h}$ before processing for Fgf17 (green signal) and pErk (red signal) double immunofluorescence (Fig. 9B). In both WT and $H s 2 s t^{-1-}$ cultures, Fgf17 protein was detectable adjacent to the edge of the bead (green signal) and this activated ERK phosphorylation in a similar pattern (red signal) with no obvious differences between WT and $H s 2 s t^{-1-}$, indicating that $H s 2 s t^{-1-}$ CSB tissue is competent to respond to Fgf17 (Fig. 9B, top row). The lack of Fgf17 or pERK signal in the BSA control (Fig. 9B, bottom row) confirms Fgf17 antibody specificity and that pERK activation was specifically induced by exogenously applied Fgf17. We performed Sox9/ BrdU analysis (exactly as described above for the FGFi experiments; Fig. 7) to assess the impact of experimentally introduced

\footnotetext{
(Figure legend continued.) $(\boldsymbol{J}, \boldsymbol{K} \mathbf{1}-\mathbf{K} \mathbf{3}, \mathbf{L 1}-\mathbf{L} \mathbf{3})$ and Fgf17 protein $(\mathbf{M}, \mathbf{N 1}-\mathbf{N} \mathbf{3}, \mathbf{0 1}-\mathbf{0 3})$ expression (red) relative to $\mathrm{GFP}^{+}$Zic4-lineage cells (indicated with white arrows) at the GW (K1-K3, N1-N3) and IG (L1-L3, 01-03) of WT E14.5 embry0s. P, E14.5 expression of Hs2st by LacZ staining. Hs $2 s t$ is expressed most highly at the $\mathrm{VZ}$, with decreasing expression toward the pial surface. $\mathbf{Q}-\boldsymbol{V}$, Fgf17 protein $(\boldsymbol{Q}, \boldsymbol{R})$ and mRNA (S) expression at the E14.5 CSB of WT and $H_{s 6 s t 1^{-1}-}$ embryos. Fgf17 protein is expressed at low levels at the CSB of WT embryos (Q1, R1). In Hs6st $1^{-1-}$ embryos, the protein expression domain is similar to WT (Q2, R2). Fgf17 mRNA expression is unchanged between WT and $H_{s} 6 s t 1^{-1-}$ embryos $(\mathbf{S 1}, \mathbf{S 2}) . \mathbf{T}-\boldsymbol{V}$, Fgf17 protein $(\boldsymbol{T}, \boldsymbol{U})$ and mRNA (V) expression at the E16.5 CSB of WT and Hs6st $1^{-1-}$ embryos. Fgf17 protein is expressed at very low levels at the CSB of both WT $(\boldsymbol{I 1}, \boldsymbol{U} \mathbf{1})$ and $\mathrm{Hs}_{5 \mathrm{st1}}{ }^{-1-}$ $\left(\boldsymbol{T} 2\right.$, U2) embryos. Fgf17 mRNA expression is unchanged between WT (V1) and Hs6st ${ }^{-1-}$ (V2) embryos. W, Quantification of Fgf17 immunofluorescence signal at E14.5 CSB in WT (blue bar, $n=3$ embryos), Hs2st ${ }^{-1-}$ (green bar, $n=3$ embryos), and Hs6st1 ${ }^{-1-}$ (purple bar, $n=3$ embryos). Fgf17 protein level is significantly increased compared with WT in $\mathrm{Hs}_{\mathrm{s}} \mathrm{st} \mathrm{-}^{-1-}$ embryos ( ${ }^{*} p<0.05$ on graph, $F_{(2,9)}=13.83, p=0.0018$, ANOVA, post hoc $t$ tests: WT vs $H s 2 s t^{-l-}, t_{(4)}=-4.22, p=0.014, t$ test; and WT vs Hs6st $1^{-1-}, t_{(6)}=-0.98, p=0.36$, $t$ test). Boxed areas in $\boldsymbol{A}, \boldsymbol{D}, \boldsymbol{G}, \boldsymbol{Q}$, and $\boldsymbol{T}$ are shown at higher magnification in $\boldsymbol{B}, \boldsymbol{E}, \boldsymbol{H}, \boldsymbol{R}$, and $\boldsymbol{U}$, respectively. Scale bars: $A, D, G, Q, T, 200 \mu \mathrm{m} ; \boldsymbol{B}, \boldsymbol{C}, \boldsymbol{E}, \boldsymbol{F}, \boldsymbol{H}, \boldsymbol{I}, \boldsymbol{R}, \boldsymbol{S}, \boldsymbol{U}, \boldsymbol{V}, J, M, \boldsymbol{P}, 100 \mu \mathrm{m} ; \boldsymbol{K}, \boldsymbol{L}, \mathbf{N}$, $0,10 \mu \mathrm{m}$.
}

Fgf17 on astroglial translocation to the midline in WT CSB slices after $48 \mathrm{~h}$ in culture and the results were dramatic. The side with the Fgf17-bead showed many more Sox $9^{+}$(red) cells in the IG region (large arrow on right side of Fig. 9 C) than the side with the BSA bead (smaller arrow on left side of Fig. 9C). Quantification of Sox ${ }^{+}$;BrdU ${ }^{+}$(yellow) cells (Fig. 9D shows higher magnification of IG region) confirmed a significant increase in astroglial translocation to the midline along the rostrocaudal axis on the side exposed to Fgf17 [Fig. 9E, cf. green (Fgf17) with black (control) lines]. An important function of IG glia is to secrete Slit2 and repulsively guide $\mathrm{CC}$ axons in the correct trajectory across the midline. At E16.5, Slit2 mRNA is normally expressed in the IG region and, in $H s 2 s t^{-1-}$ embryos, the midline Slit2 expression domain is expanded (cf. Fig. 2C,E and D, F; Slit2 expression domain is bracketed). Experimentally introduced Fgf17 is sufficient to phenocopy this aspect of the Hs2st ${ }^{-1-}$ phenotype in our ex vivo assay because the side exposed to the Fgf17 bead has a much larger Slit2 domain than the BSA-treated side [cf. left (control) and right (Fgf17) bracketed areas in Fig. 9F], consistent with precocious translocation of excessive numbers of Slit ${ }^{+}$IG glia.

We conclude that $H s 2 s t^{-1-}$ CSB tissue is competent to respond to Fgfl7 protein and abnormally high levels of Fgfl7 protein are sufficient to phenocopy the Hs2st ${ }^{-1-}$ astroglial translocation phenotype consistent with the model presented in Figure 10.

\section{Hs2st selectively facilitates physical interaction between Fgf17 protein and $\mathrm{HS}$}

Our in vivo data show that Hs2st suppresses the levels of Fgf17 protein and that this represents a selective interaction between Hs2st-mediated 2-O HS sulfation and Fgf17 protein levels in vivo because Hs2st does not suppress the levels of the closely related Fgf8 protein, and Hs6st1, which catalyzes 6-O HS sulfation, does not suppress Fgf17 protein levels (Clegg et al., 2014; Chan et al., 2017) (Fig. 8). However, these in vivo experiments do not resolve whether differential sulfation has a correspondingly direct selective effect on the physical interaction between HS and Fgf17. To test the hypothesis that Hs2st has a selective effect on the binding of Fgf17 protein to HS molecules, we turned to a biochemical assay, the LACE assay, which probes the physical interaction between HS and FGF proteins by quantifying the ability of endogenous HS in tissue sections to form Fgf:Fgfr:HS complexes with exogenously added Fgf protein and Fgfr ectodomain fused to an Fc tag for immunofluorescent detection (Allen et al., 2001; Chan et al., 2015). We used the Fgf17:Fgfr1 LACE assay to compare the binding of Fgf17 protein to HS in WT, Hs2st ${ }^{-1-}$, and Hs6st1 ${ }^{-1-}$ CSB tissue at E14.5 and E16.5 to test the hypothesis that Fgf17:HS physical interaction is selectively sensitive to loss of 2-O HS sulfation in $H s 2 s t^{-1-}$ tissue (Fig. 11A-J,O). We used the Fgf8:Fgfr3 LACE assay to compare the binding of Fgf8 protein to HS in WT and $H s 2 s t^{-1-}$ CSB tissue at E14.5 to test the hypothesis that the Fgf8:HS physical interaction is insensitive to loss of 2-O HS sulfation in $H s 2 s t^{-1-}$ tissue (Fig. $11 K-N, P$ ).

In both E14.5 and E16.5 WT tissue, the Fgf17:Fgfr1 and Fgf8: Fgfr3 LACE assays produced a strong LACE signal (Fig. 11 A, F,K, with higher magnification of boxed areas enclosing CSB region shown in $\left.A^{\prime}, F^{\prime}, K^{\prime}\right)$. Control experiments show this LACE signal was drastically reduced by pretreating the tissue with heparitinase to digest HS (Fig. $11 D, I, M$, with higher magnification of CSB in $\left.D^{\prime}, I^{\prime}, M^{\prime}\right)$ or omitting Fgf17 or Fgf8 protein from the assay (Fig. $11 E, J, N$, with higher magnification of CSB in $\left.E^{\prime}, J^{\prime}, N^{\prime}\right)$. Together, these controls confirm that the LACE signal provides a specific readout of the interaction between each FGF protein and HS 
A

\section{Ectopic expression of Fgf17}

\section{E14.5 1hr BrdU pulse}

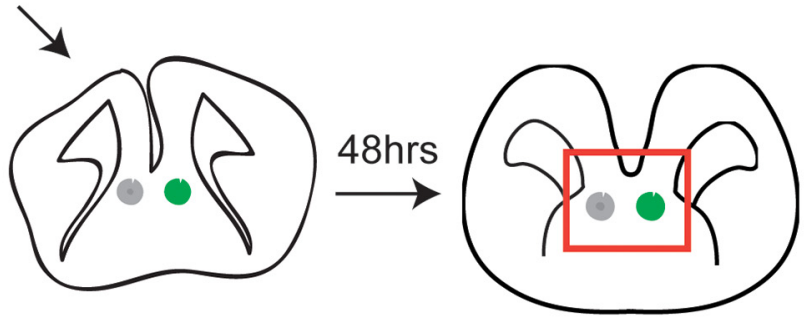

B
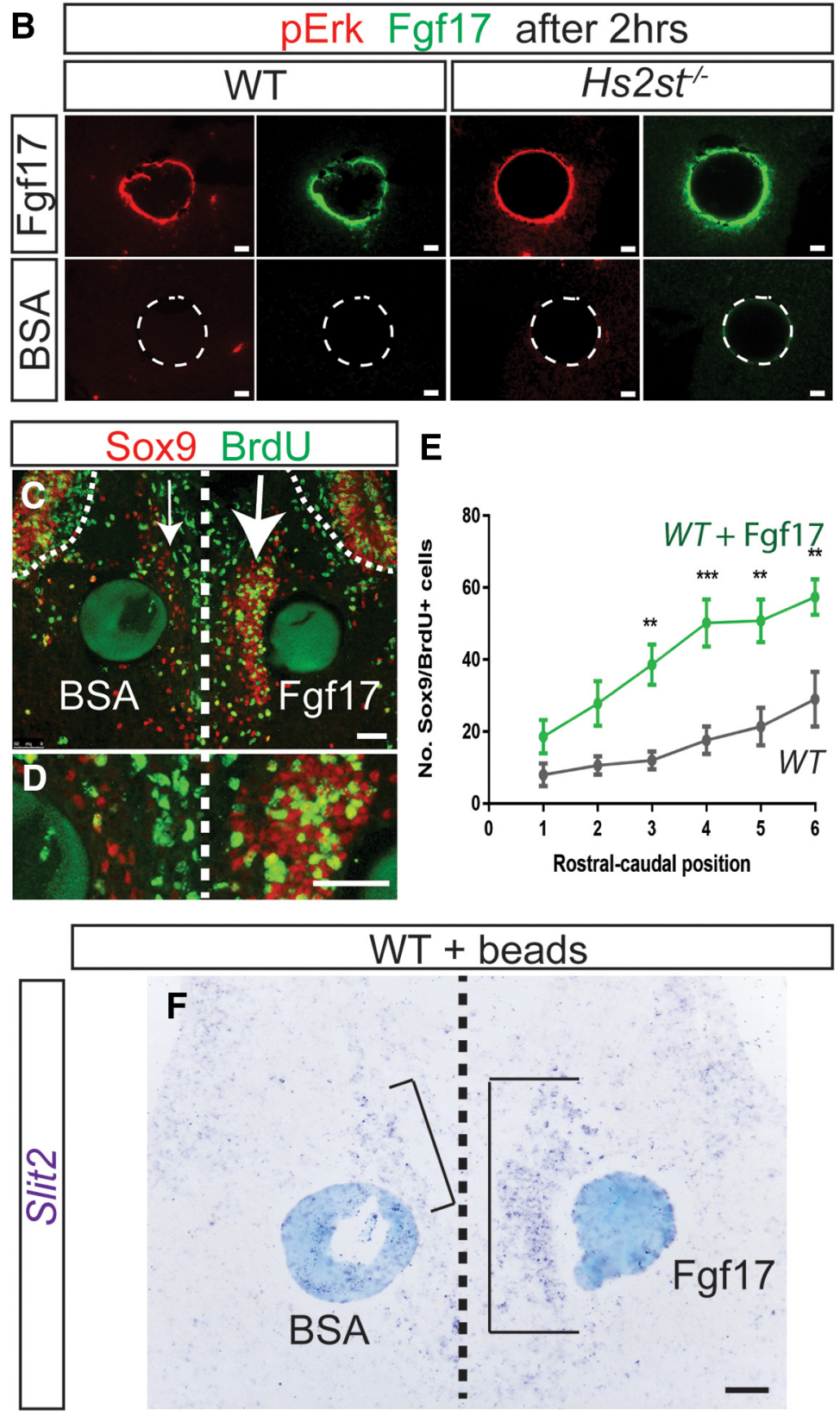

Figure 9. Fgf17-bead experiment. $A$, Experimental outline of Fgf17 protein bead experiment in WT embryos. Pregnant females were injected at E14.5 with a BrdU pulse and CSB slices collected. One Fgf17 and one BSA bead were added to each side of the midline. $\boldsymbol{B}$, Fgf17 protein and pErk after $2 \mathrm{~h}$ in culture. In both WT and $\mathrm{Hs}_{2} \mathrm{st}^{-{ }^{-}-}$CSB slices, Fgf17 and pErk are seen in tissue surrounding the Fgf17 bead. Staining for either is absent around the BSA bead (demarcated by dotted circle). $C$, Immunofluorescence for BrdU and Sox9 was performed on WT slices after $48 \mathrm{~h}$ in culture; curved dotted lines indicate the basal edge of the VZ and straight dotted line indicates the midline. D, Higher magnification of the arrowed regions in C. E, Quantification of Sox ${ }^{+} / \mathrm{BrdU}^{+}$ molecules. To determine the effect of differential sulfation on the physical interaction between HS and Fgf8 or Fgf17, we investigated how the LACE signal was affected when the assay was performed on $H s 2 s t^{-1-}$ and $H s 6 s t 1^{-1-}$ tissue. As predicted by our hypothesis, the binding of Fgf17 to HS is selectively sensitive to 2-O HS sulfation because we found that the Fgf17:Fgfr1 LACE signal was much weaker than WT in $H s 2 s t^{-1-}$ tissue (cf. $B, B^{\prime}, G, G^{\prime}$ and $\left.A, A^{\prime}, F, F^{\prime}\right)$, but similar to WT in $H s 6 s t 1^{-1-}$ tissue (cf. $C, C^{\prime}, H, H^{\prime}$ and $\left.A, A^{\prime}, F, F^{\prime}\right)$. Quantification of Fgf17: Fgfr1 LACE signal intensity in Figure 110 shows a significant $\sim 4$-fold reduction in $H s 2 s t^{-1-}$ (green bar) compared with WT (blue bar), but no significant difference from WT in Hs6st1 ${ }^{-1-}$ (purple bar). As predicted by our hypothesis that the binding of Fgf8 to HS is not sensitive to 2-O HS sulfation, we found that there was no difference in the Fgf8:Fgfr3 LACE signal between WT and $H s 2 s t^{-1-}$ tissue (cf. Fig. $11 K, K^{\prime}$ and $\left.L, L^{\prime}\right)$. Quantification of Fgf8: Fgfr3 LACE signal intensity in Figure $11 P$ shows no significant difference between $H s 2 s t^{-1-}$ (green bar) compared with WT (blue bar). These LACE results are summarized schematically in Figure $11 Q$, which shows that, of the five HST genotype and FGF ligand permutations tested, only the Fgf17:HS physical interaction was sensitive to the Hs2st genotype, as predicted by the hypothesis that 2-O HS sulfation has a specific effect on the ability of HS to bind Fgf17.

\section{Discussion}

Embryonic CC development involves multiple cell and molecular events that ultimately guide callosal axons across the telencephalic midline to connect with their synaptic targets in the contralateral hemisphere. Three subpopulations of midline astroglia play pivotal roles in guiding callosal axons across the telence-

\footnotetext{
double-labeled cells in WT CSB slice cultures with Fgf17 or BSA bead. The Fgf17 bead significantly increased the number of Sox ${ }^{+} / \mathrm{BrdU}^{+}$cells that exit the VZ and moved toward the IG (significant differences indicated on graph as ${ }^{* *} p<0.05$, ${ }^{* * *} p<0.001$ ) at the four caudal-most positions ( $n=5 \mathrm{em}$ bryos; $F_{(1,48)}=65.63, p=0.000000000155$, two-way ANOVA, followed by $t$ test with Sidak's correction for multiple comparisons for Fgf17-bead vs BSA-bead at each rostralcaudal position: position $1, t_{(48)}=1.45, p=0.63, t$ test; position $2, t_{(48)}=2.36, p=0.13, t$ test; position $3, t_{(48)}=3.65$, $p=0.0039$, $t$ test; position $4, t_{(48)}=4.47, p=0.0003, t$ test; position $5, t_{(48)}=4.03, p=0.0012, t$ test; and position 6 , $t_{(48)}=3.89, p=0.0018, t$ test). $\boldsymbol{F}$, Slit2 expression in slices cultured with Fgf17 and BSA beads. Scale bars, $100 \mu \mathrm{m}$.
} 
phalic midline. MZ glia facilitate fusion of the cerebral hemispheres and provide a substrate for crossing callosal axons, whereas Slit2 ${ }^{+}$IG and GW astroglia channel crossing axons into the correct path by Robo/Slit-mediated chemorepulsion (Shu and Richards, 2001; Bagri et al., 2002; Shu et al., 2003; Gobius et al., 2016). These astroglial populations originate from RGCs born in the VZ of the septal midline and either remain in the $\mathrm{VZ}$ at the GW or translocate in response to FGF signals, of which Fgf8 appears to be particularly important, to the pial surface of the telencephalic midline (MZ and IG astroglia) (Smith et al., 2006; Moldrich et al., 2010; Clegg et al., 2014; Gobius et al., 2016). Both Slit $2^{+}$IG and Slit $2^{-}$MZ astroglia are essential for CC development and both of these astroglial populations originate from the septal VZ Zic4 lineage, so the lack of an overt CC phenotype in $H s 2 s t^{\mathrm{Fl} / \mathrm{Fl}} ; Z_{i c 4}{ }^{\mathrm{Cre}}$ embryos following conditional knock-out of Hs2st in the Zic4 lineage indicates that neither MZ or IG astroglial precursors have a cell-autonomous requirement for $\mathrm{Hs} 2 \mathrm{st}$ to translocate in appropriate numbers. In $H s 2 s t^{-1-}$ embryos, there is an expansion of the Slit2 expression domain at the CSB pial surface coinciding with increased Sox $9^{+}$glial cells and this is phenocopied by application of exogenous Fgf17 to $\mathrm{Hs} 2 \mathrm{st} \mathrm{H}^{+/+} \mathrm{CSB}$ ex vivo, strongly suggesting that increased numbers of Slit $2^{+}$glial cells at the midline reflect excessive GW $\rightarrow$ IG somal translocation enlarging the IG (current study). We cannot rule out the possibility that disrupted MZ glial translocation also contributes to the $H s 2 s t^{-1-}$ phenotype, although this would not alter our conclusion that Hs2st plays a non-cell-autonomous role in the Zic4-lineage astroglial translocation phenotype. Our model (Fig. 10) posits that ectopic Slit $^{+}$astroglia at the midline block the transit of CC axons. In principle, this could be tested by rescuing the CC axon midline crossing in $H s 2 s t^{-1-} ;$ Slit2 $2^{-1-}$ embryos (along similar lines to the Slit2 genetic rescue of the $H s 6 s t 1^{-1-}$ phenotype that we reported in $H s 6 s t 1^{-1-}$;Slit2 $2^{-1-}$ embryos; Conway et al., 2011). However, in contrast to the fully penetrant $(100 \%) H s 6 s t 1^{-1-}$ CC phenotype, the partial penetrance $(\sim 50 \%)$ of the $H_{s} 2 s t^{-1-}$ CC phenotype introduces a confounding factor of distinguishing "rescued" from "unaffected" $H s 2 s t^{-1-}$ embryos, a problem that would be compounded if only a proportion of embryos destined to be affected were rescued (Conway et al., 2011; Clegg et al., 2014), so a prohibitively large number of animals would be required to demonstrate a statistically significant rescue.

Eliminating HS (Ext1 mutagenesis) compared with 2-O HS sulfation (Hs2st mutagenesis) from the same cell lineages allowed us to distinguish physiological functions generally attributable to HS from those specifically requiring 2-O HS sulfation by comparing the Ext1 and Hs2st phenotypes. We found that, although Zic4-lineage cells were unable to support CC development when they lacked HS ( $\mathrm{Zic}^{\mathrm{Cre}}{ }^{\mathrm{C}}$ Ext $1^{\mathrm{F} / \mathrm{Fl}}$ embryos), there was no similar requirement for 2-O HS sulfation in the Zic4 lineage (Zic4 ${ }^{\mathrm{Cre}}$; $H s 2 s t^{\mathrm{Fl} / \mathrm{Fl}}$ embryos), indicating that Zic4-lineage cells require HS but that 2-O HS sulfation is dispensable for their contribution to CC development, specifically the ability of astroglial precursors to cell autonomously sense translocation signals. We found that HS and 2-O HS sulfation are both required in the Emxl lineage
$\left(E m x 1^{\mathrm{CreER}} ; E x t 1^{\mathrm{Fl} / \mathrm{Fl}}\right.$ and $E m x 1^{\mathrm{CreER}} ; H s 2 s t^{\mathrm{F} / \mathrm{Fl}}$ embryos), although the axonal and astroglial phenotypes were not identical. Somewhat counter-intuitively, removing HS completely from the Emx1 lineage (Emx1 ${ }^{\mathrm{CreER}} ; E x t 1^{\mathrm{F} / / \mathrm{Fl}}$ embryos) has a less severe effect on the distribution of $\mathrm{GFAP}^{+}$midline astroglia than preserving HS but specifically blocking it's 2-O sulphation $\left(E m x 1^{\mathrm{CreER}} ; H s 2 s t^{\mathrm{F} / / \mathrm{F} 1}\right.$ embryos) with the more subtle disruption to HS causing the more pronounced accumulation of astroglia at the pial surface. We speculate that completely removing HS from the Emx1 lineage results in a general destabilization of FGF protein gradients thus mitigating precocious somal translocation by Zic4 lineage astroglial precursors (Qu et al., 2011, 2012; Shimokawa et al., 2011; Chan et al., 2017). The relatively normal midline astroglial organization in $E m x 1^{\mathrm{CreER}} ; \mathrm{Ext1}^{\mathrm{F} / \mathrm{Fl}}$ embryos poses the question of whether glial disorganization is a major contributor to their CC agenesis phenotype. In Emx1 ${ }^{\text {CreER}}$; $H s 2 s t^{\mathrm{F} / \mathrm{Fl}}$ embryos, the Probst bundles form right next to the midline, consistent with our hypothesis that ectopic Slit $2^{+}$astroglia at the midline are repelling CC axons from crossing the midline (Conway et al., 2011 and current study). In contrast, the Probst bundles in $E m x 1^{\mathrm{CreER}} ;{ }^{\mathrm{E} x t 1^{\mathrm{F} / \mathrm{Fl}}}$ embryos form much more lateral to the midline at some distance from the IG, indicating that CC axons are misrouted at an earlier stage of their navigation than in $E m x l^{\mathrm{CreER}} ; H s 2 s t^{\mathrm{Fl} / \mathrm{Fl}}$ embryos. HS is required cell autonomously for navigating axons to respond to axon guidance molecules, including Netrin1 and Slit2 (Piper et al., 2006; Matsumoto et al., 2007). A plausible explanation is that, in Emx1 ${ }^{\mathrm{CreER}}$; $E x t 1^{\mathrm{F} / \mathrm{F} 1}$ embryos, the Emx1-lineage HS-deficient CC axons cannot respond appropriately to guidance cues that would normally guide them toward the midline and are already misrouted before they come under the influence of the midline astroglia. In contrast, $H s 2 s t^{-1-} \mathrm{CC}$ axons express HS lacking 2-O sulfation, which does not affect their ability to respond to guidance cues (current study), so they reach the midline but are prevented from crossing by the ectopic Slit $2^{+}$glia in the expanded IG.

Biochemical (LACE) data show that physical interaction between Fgf17 and HS is facilitated by Hs2st (but not Hs6st1) and that Hs2st facilitates physical interaction between HS and Fgf17 (but not Fgf8), suggesting a molecular mechanism underpinning 

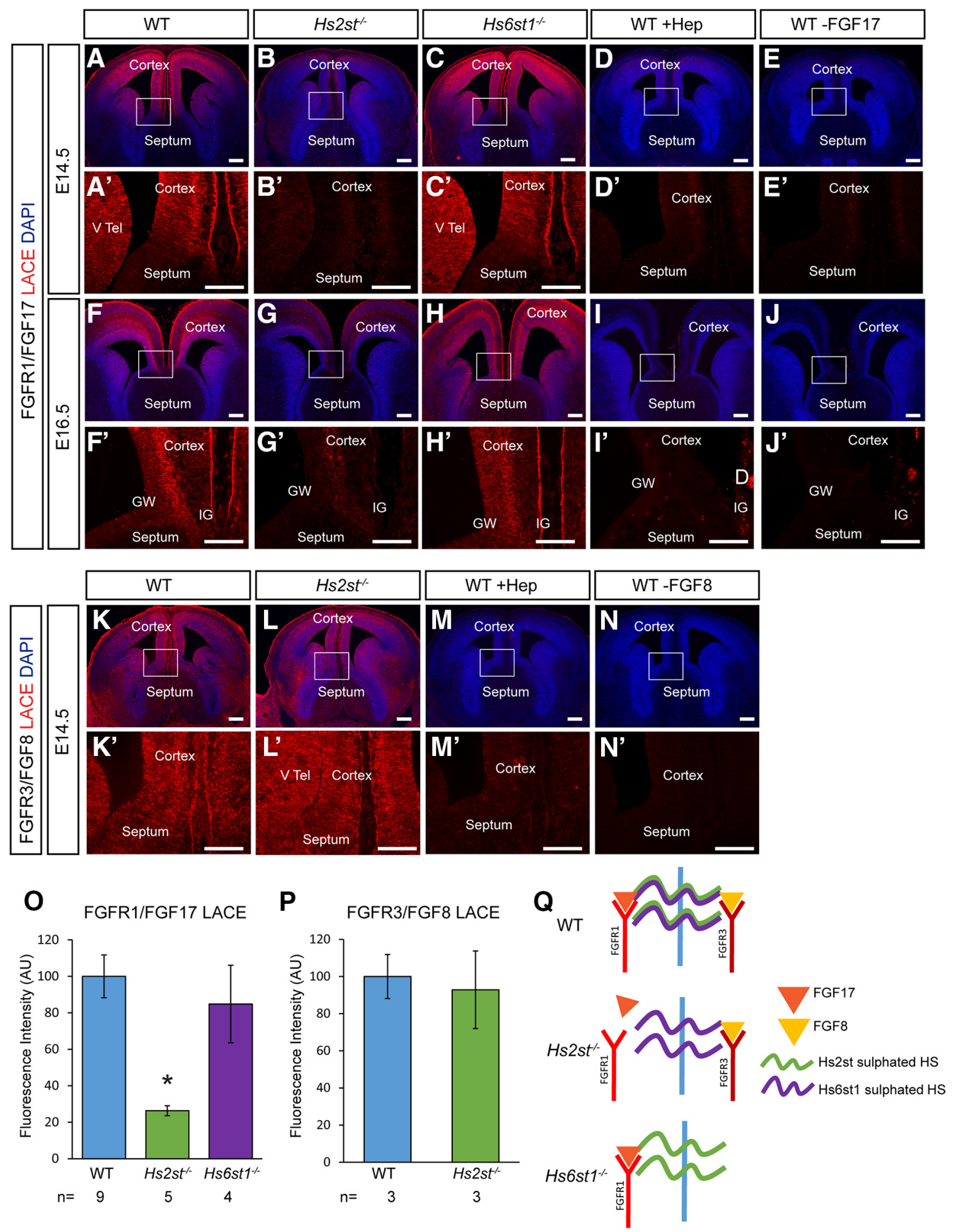

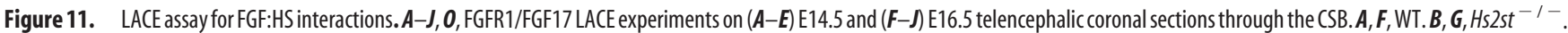
$\boldsymbol{C}, \boldsymbol{H}, H_{s} 6 s t 1^{-I-}$. D, I, WT sections pretreated with heparinitase to digest HS. $\boldsymbol{E}, \boldsymbol{J}$, WT sections with FGF17 omitted from the LACE assay. O, Quantification of FGF17/FGFR1 LACE signal in WT (blue bar, $n=9$ embryos), $H_{s} 2 s t^{-1-}$ (green bar, $n=5$ embryos), and Hs6st1 ${ }^{-1-}$ (purple bar, $n=4$ embryos), showing a significant decrease ${ }^{*} p<0.05$ on graph) in $H_{s} 2 s t^{-1-}$ embryos $F_{(2,15)}=$ $8.62, p=0.0032$, ANOVA, followed by post hoc $t$ test: WT vs Hs $2 s t^{-1-}, t_{(9)}=6.11, p=0.014, t$ test; WT vs Hs6st ${ }^{-1-}, t_{(5)}=0.63, p=0.56, t$ test). $\boldsymbol{K}_{-N} \boldsymbol{N}, \boldsymbol{P}$, FGFR3/FGF8 LACE experiments on E14.5 telencephalic coronal sections through the CSB. $\boldsymbol{K}$, WT. L, Hs 2st ${ }^{-1-}$. M, WT sections pretreated with heparinitase to digest HS. $\boldsymbol{N}$, WT sections with FGF8 omitted from the LACE assay. $\boldsymbol{P}$, Quantification of FGF8/FGFR3 LACE signal in WT (blue bar, $n=3$ embryos) and $H s 2 s t^{-1-}$ (green bar, $n=3$ embryos) showing no significant difference $\left(t_{(3)}=0.29, p=0.76, t\right.$ test). Numbers of embryos of each genotype analyzed indicated under bars. Q, Summary diagram. FGFR1/FGF17/HS complex formation is equally supported by WT and $\mathrm{Hs}_{\mathrm{s}} \mathrm{st} \mathrm{T}^{-1-}{ }^{-1} \mathrm{HS}$ but less so by $\mathrm{Hs} 2 \mathrm{st} \mathrm{C}^{-1-}$ $\mathrm{HS}$, whereas FGFR3/FGF8/HS complex formation is equally supported by WT and Hs2st ${ }^{-1-} \mathrm{HS}$, showing that the FGF17:HS physical molecular interaction is selectively dependent on 2-0 HS sulfation. $\boldsymbol{A}^{\prime}-\boldsymbol{N}^{\prime}$, Higher magnification showing the CSB region boxed in $\boldsymbol{A}-\boldsymbol{N}$ (note that the DAPI channel is not shown in the higher-magnification images to improve visualization of the LACE signal). Scale bars, $200 \mu \mathrm{m}$. 
Hs2st selectively suppressing levels of Fgf17 in vivo (Allen and Rapraeger, 2003; Clegg et al., 2014; Chan et al., 2015, 2017; current study). We speculate that Hs2st exerts its selective effect on Fgf17 protein levels because HS lacking 2-O HS sulfation has reduced affinity for Fgf17 (but not Fgf8), so increasing the halflife of Fgf17 (but not Fgf8) in the ECM by selectively reducing the rate that Fgf17 protein is cleared by HS-mediated receptormediated endocytostis of canonical FGFs while leaving Fgf8 unaffected (Yu et al., 2009). Our conditional mutagenesis experiments clearly demonstrate there is non-cell-autonomous requirement for $H s 2 s t$ in astroglial precursor translocation in Emx $1^{\mathrm{CreER}} ; H s 2 s t^{\mathrm{F} / \mathrm{Fl}}$ embryos; however, the reduced efficiency of HS:Fgf17:Fgfr 1 complex formation in the $H s 2 s t^{-1-}$ LACE assay implies that $H s 2 s t$ might also play a cell-autonomous role in the response to Fgf17 protein. We speculate that, even if $H s 2 s t^{-1-}$ astroglial precursors are less sensitive to Fgf17 than their WT counterparts, their translocation to the midline is primarily driven by Fgf8, so it is not significantly affected in Zic4 ${ }^{\text {Cre }}$; $H s 2 s t^{\mathrm{Fl} / \mathrm{Fl}}$ embryos. A putative reduced sensitivity of $H s 2 s t^{-l-}$ astroglial precursor cells to Fgf17 also begs the question of how elevated Fgf17 could trigger precocious glial translocation in $H_{s} 2 \mathrm{st}^{-1-}$ embryos. The Fgf17 bead assay experiment shows that $H s 2 s t^{-1-}$ cells retain competence to respond to Fgf17 by phosphorylating ERK and LACE data show that HS devoid of 2-O HS sulfation still interacts with Fgf17, albeit with reduced efficiency. Therefore, the explanation that best fits our experimental data is that increased Fgf17 protein levels in $H s 2 s t^{-1-}$ embryos override any reduction in competency of $H s 2 s t^{-1-}$ cells to respond to Fgf17 protein and the net effect is elevated FGF/ERK signaling and consequent precocious astroglial translocation.

This study makes two major novel contributions to our understanding of the cell and molecular roles of differential HS sulfation in the regulation of forebrain development. First, a primary cellular role of 2-O HS sulfation in vivo is not to modulate the competence of astroglial precursor cells to respond to translocation signals by a cell-autonomous mechanism (as would be predicted by the classic role for HS in modulating the formation of the FGF:FGFR:HS receptor complex on the surface of responding cells), but instead to regulate the supply of translocation signals to astroglial precursors by a non-cell-autonomous mechanism. Second, the interaction between 2-O-sulfated HS and Fgf17 protein is selective because it does not apply to the closely related Fgf8 protein or to 6-O HS sulfation catalyzed by Hs6st1. The most parsimonious explanation linking these cell and molecular events is that higher than normal levels of Fgf17 protein at the CSB of $H s 2 s t^{-1-}$ embryos causes the precocious astroglial precursor translocation phenotype and subsequent misrouting of CC axons (Fig. 10). Our rescue of the Hs2st ${ }^{-1-}$ precocious astroglial precursor translocation phenotype ex vivo by generic pharmacological inhibition of FGF signaling with SU5402 directly supports the hypothesis that hyperactive FGF/ ERK signaling causes the phenotype. Given the well known role of FGF/ERK signaling in triggering astroglial precursor translocation to the IG, our findings that exogenously applied Fgf17 protein is sufficient to phenocopy the $H s 2 s t^{-1-}$ astroglial precursor translocation phenotype and that $H s 2 s t^{-1-}$ CSB cells activate ERK in response to Fgf17 protein, it is extremely unlikely that increased Fgf17 protein levels in vivo would not result in ERK hyperactivation and consequent precocious astroglial precursor translocation in $\mathrm{Hs}_{\mathrm{S}} \mathrm{st} \mathrm{-}^{-1-}$ embryos. However, the current study does not provide formal proof that the elevated levels of Fgf17 protein are solely responsible for the FGF/ERK hyperactivation or precocious astroglial precursor translocation phenotypes in
$H s 2 s t^{-1-}$ embryos and we were unable to design an experiment that could further discriminate between the functions of Fgf17 and Fgf8 and directly test functional selectivity of Hs2st for Fgf17 in this context. We considered using a classic rescue experiment strategy by genetically reducing $\mathrm{Fg} f 17$ dosage in $\mathrm{Hs}_{\mathrm{s}} \mathrm{s}^{-1-} \mathrm{em}$ bryos ( $F g f 17^{-1-} ; H s 2 s t^{-1-}$ rescue), but elected not to because, at best, it would provide equivocal evidence either for or against the hypothesis that 2-O-sulfated HS interacts selectively with Fgf17 protein. FGF/ERK hyperactivation caused by overexpression of a particular FGF protein can be rescued by any experimental manipulation that restores ERK signaling to normal levels and not uniquely by restoring the levels of the FGF protein that underpins the phenotype. Specifically, reducing Fof 17 dosage could elicit a rescue of ERK hyperactivation and collateral phenotypes at the $H s 2 s t^{-1-}$ CSB by reducing FGF/ERK signaling output regardless of whether abnormally high Fgf17 bioavailability was the primary cause. Analogously, we interpret rescue of the $\mathrm{Hs}_{\mathrm{S}} \mathrm{st} \mathrm{T}^{-1-}$ precocious astroglial precursor translocation phenotype in $\mathrm{Hs}_{s} \mathrm{st} \mathrm{1}^{-1-}$; $F g f 8^{\text {neo/neo }}$ embryos as evidence that $H s 6 s t 1$ normally acts to keep FGF/ERK signaling in check rather than as evidence for a selective genetic interaction between Fgf8 and Hs6st1 (Clegg et al., 2014). Conversely, failure to rescue the $\mathrm{Hs} 2 \mathrm{st} \mathrm{t}^{-1-}$ phenotype in $\mathrm{Fg} f 17^{-1-}$; $H s 2 s t^{-1-}$ embryos (or using other methods to reduce Fgf17 protein levels or functionality) would not falsify the hypothesis that increased Fgf17 bioavailability caused the $H s 2 s t^{-1-}$ phenotype because there are several alternative explanations. When we used a similar strategy in a similar context to rescue the Hs6st1 ${ }^{-1-}$ astroglial precursor precocious translocation phenotype by genetically reducing $F g f 8$ dosage, the rescue was only successful in a minority of isogenic $H s 6 s t 1^{-1-} ; F g f 8^{\text {neo/neo }}$ embryos and a likely explanation is that compensatory mechanisms act when Fgfgene dosage is manipulated (Clegg et al., 2014). Such compensation will generate false-negative results, making it unsafe to interpret unrescued $\mathrm{Fg} f 7^{-1-} ; \mathrm{Hs} 2 \mathrm{st} \mathrm{t}^{-1-}$ embryos as falsifying the hypothesis that the phenotype is underpinned by excess Fgf17 protein. There are additional technical confounds that could lead to false negatives because a rescue likely requires precise restoration of normal Fgf17 protein levels (so no rescue could reflect technical failure to restore Fgf17 protein levels to normal) and, in any case, the CC phenotype of $\mathrm{Fg} f 17^{-1-}$ embryos has not been thoroughly characterized, so $H s 2 s t^{-1-} ; \mathrm{Fg} f 17^{-1-}$ phenotypes may be problematic to interpret (Cholfin and Rubenstein, 2007, 2008). In addition to not being decisive for or against selectivity, demonstrating genetic interaction between $\mathrm{Hs} 2 \mathrm{st}$ and $\mathrm{Fgfl} 17$ would not provide insight into whether the interaction was molecularly direct, in contrast to the biochemical LACE data that we present in the current study.

The closely related $F g f 8$ subfamily members $F g f 17$ and $F g f 8$ are both transcribed by cells in the CSB region, yet have different roles in forebrain development with available evidence, although this does not rule out a role for $F g f 17$, suggesting that $F g f 8$ is the primary driver of astroglial precursor translocation required for CC development (Cholfin and Rubenstein, 2007, 2008; Moldrich et al., 2010; Toyoda et al., 2010; Gobius et al., 2016). The independent suppression of Fgf17 and Fgf8 protein levels by HS modified by Hs2st and Hs6st1, respectively, may have facilitated the evolution of this system by providing a mechanism to tilt the Fgf17:Fgf8 protein balance to give Fgf8 the more dominant role in regulating astroglial precursor translocation (Clegg et al., 2014; Chan et al., 2017, current study). In this sense, there are parallels to other negative regulatory strategies, such as microRNAs that function by protecting cells from the expression of particular proteins that would be detrimental if expressed. 


\section{References}

Allen BL, Rapraeger AC (2003) Spatial and temporal expression of heparan sulfate in mouse development regulates FGF and FGF receptor assembly. J Cell Biol 163:637-648. CrossRef Medline

Allen BL, Filla MS, Rapraeger AC (2001) Role of heparan sulfate as a tissuespecific regulator of FGF-4 and FGF receptor recognition. J Cell Biol 155:845-858. CrossRef Medline

Bagri A, Marín O, Plump AS, Mak J, Pleasure SJ, Rubenstein JL, TessierLavigne M (2002) Slit proteins prevent midline crossing and determine the dorsoventral position of major axonal pathways in the mammalian forebrain. Neuron 33:233-248. CrossRef Medline

Balasubramanian R, Zhang X (2016) Mechanisms of FGF gradient formation during embryogenesis. Semin Cell Dev Biol 53:94-100. CrossRef Medline

Belenkaya TY, Han C, Yan D, Opoka RJ, Khodoun M, Liu H, Lin X (2004) Drosophila dpp morphogen movement is independent of dynaminmediated endocytosis but regulated by the glypican members of heparan sulfate proteoglycans. Cell 119:231-244. CrossRef Medline

Bullock SL, Fletcher JM, Beddington RS, Wilson VA (1998) Renal agenesis in mice homozygous for a gene trap mutation in the gene encoding heparan sulfate 2-sulfotransferase. Genes Dev 12:1894-1906. CrossRef Medline

Chan WK, Howe K, Clegg JM, Guimond SE, Price DJ, Turnbull JE, Pratt T (2015) 2-O Heparan sulfate sulfation by Hs2st is required for Erk/Mapk signaling activation at the mid-gestational mouse telencephalic midline. PLoS One 10:e0130147. CrossRef Medline

Chan WK, Price DJ, Pratt T (2017) FGF8 morphogen gradients are differentially regulated by heparan sulfotransferases Hs2st and Hs6st1 in the developing brain. Biol Open 6:1933-1942. CrossRef Medline

Cholfin JA, Rubenstein JL (2007) Patterning of frontal cortex subdivisions by Fgf17. Proc Natl Acad Sci U S A 104:7652-7657. CrossRef Medline

Cholfin JA, Rubenstein JL (2008) Frontal cortex subdivision patterning is coordinately regulated by Fgf8, Fgf17, and Emx2. J Comp Neurol 509: 144-155. CrossRef Medline

Christian JL (2012) Morphogen gradients in development: from form to function. Wiley Interdiscip Rev Dev Biol 1:3-15. CrossRef Medline

Clegg JM, Conway CD, Howe KM, Price DJ, Mason JO, Turnbull JE, Basson MA, Pratt T (2014) Heparan sulfotransferases hs6stl and hs2st keep erk in check for mouse corpus callosum development. J Neurosci 34:23892401. CrossRef Medline

Conway CD, Howe KM, Nettleton NK, Price DJ, Mason JO, Pratt T (2011) Heparan sulfate sugar modifications mediate the functions of slits and other factors needed for mouse forebrain commissure development. J Neurosci 31:1955-1970. CrossRef Medline

Donahoo AL, Richards LJ (2009) Understanding the mechanisms of callosal development through the use of transgenic mouse models. Semin Pediatr Neurol 16:127-142. CrossRef Medline

Erskine L, Williams SE, Brose K, Kidd T, Rachel RA, Goodman CS, TessierLavigne M, Mason CA (2000) Retinal ganglion cell axon guidance in the mouse optic chiasm: expression and function of robos and slits. J Neurosci 20:4975-4982. CrossRef Medline

Gobius I, Morcom L, Suárez R, Bunt J, Bukshpun P, Reardon W, Dobyns WB, Rubenstein JL, Barkovich AJ, Sherr EH, Richards LJ (2016) Astroglialmediated remodeling of the interhemispheric midline is required for the formation of the corpus callosum. Cell Rep 17:735-747. CrossRef Medline

Guillemot F, Zimmer C (2011) From cradle to grave: the multiple roles of fibroblast growth factors in neural development. Neuron 71:574-588. CrossRef Medline

Hoch RV, Clarke JA, Rubenstein JL (2015) Fgf signaling controls the telencephalic distribution of fgf-expressing progenitors generated in the rostral patterning center. Neural Dev 10:8. CrossRef Medline

Inatani M, Irie F, Plump AS, Tessier-Lavigne M, Yamaguchi Y (2003) Mammalian brain morphogenesis and midline axon guidance require heparan sulfate. Science 302:1044-1046. CrossRef Medline

Kessaris N, Fogarty M, Iannarelli P, Grist M, Wegner M, Richardson WD (2006) Competing waves of oligodendrocytes in the forebrain and postnatal elimination of an embryonic lineage. Nat Neurosci 9:173-179. CrossRef Medline

Kinnunen T, Huang Z, Townsend J, Gatdula MM, Brown JR, Esko JD, Turnbull JE (2005) Heparan 2-O-sulfotransferase, hst-2, is essential for nor- mal cell migration in Caenorhabditis elegans. Proc Natl Acad Sci U S A 102:1507-1512. CrossRef Medline

Kreuger J, Spillmann D, Li JP, Lindahl U (2006) Interactions between heparan sulfate and proteins: the concept of specificity. J Cell Biol 174:323327. CrossRef Medline

Li JP, Kusche-Gullberg M (2016) Heparan sulfate: biosynthesis, Structure, and Function. Int Rev Cell Mol Biol 325:215-273. CrossRef Medline

Loo BM, Salmivirta M (2002) Heparin/heparan sulfate domains in binding and signaling of fibroblast growth factor 8b. J Biol Chem 277:3261632623. CrossRef Medline

Loo BM, Kreuger J, Jalkanen M, Lindahl U, Salmivirta M (2001) Binding of heparin/heparan sulfate to fibroblast growth factor receptor 4. J Biol Chem 276:16868-16876. CrossRef Medline

Makarenkova HP, Hoffman MP, Beenken A, Eliseenkova AV, Meech R, Tsau C, Patel VN, Lang RA, Mohammadi M. (2009) Differential interactions of FGFs with heparan sulfate control gradient formation and branching morphogenesis. Sci Signal 2:ra55. CrossRef Medline

Matsumoto Y, Irie F, Inatani M, Tessier-Lavigne M, Yamaguchi Y (2007) Netrin-1/DCC signaling in commissural axon guidance requires cellautonomous expression of heparan sulfate. J Neurosci 27:4342-4350. CrossRef Medline

Moldrich RX, Gobius I, Pollak T, Zhang J, Ren T, Brown L, Mori S, De Juan Romero C, Britanova O, Tarabykin V, Richards LJ (2010) Molecular regulation of the developing commissural plate. J Comp Neurol 518: 3645-3661. CrossRef Medline

Niquille M, Garel S, Mann F, Hornung JP, Otsmane B, Chevalley S, Parras C, Guillemot F, Gaspar P, Yanagawa Y, Lebrand C (2009) Transient neuronal populations are required to guide callosal axons: a role for semaphorin 3C. PLoS Biol 7:e1000230. CrossRef Medline

Ornitz DM, Itoh N (2015) The fibroblast growth factor signaling pathway. Wiley Interdiscip Rev Dev Biol 4:215-266. CrossRef Medline

Piper M, Anderson R, Dwivedy A, Weinl C, van Horck F, Leung KM, Cogill E, Holt C (2006) Signaling mechanisms underlying Slit2-induced collapse of xenopus retinal growth cones. Neuron 49:215-228. CrossRef Medline

Pratt T, Sharp L, Nichols J, Price DJ, Mason JO (2000) Embryonic stem cells and transgenic mice ubiquitously expressing a tau-tagged green fluorescent protein. Dev Biol 228:19-28. CrossRef Medline

Pratt T, Conway CD, Tian NM, Price DJ, Mason JO (2006) Heparan sulfation patterns generated by specific heparan sulfotransferase enzymes direct distinct aspects of retinal axon guidance at the optic chiasm. J Neurosci 26:6911-6923. CrossRef Medline

Qu X, Carbe C, Tao C, Powers A, Lawrence R, van Kuppevelt TH, Cardoso WV, Grobe K, Esko JD, Zhang X (2011) Lacrimal gland development and Fgf10-Fgfr2b signaling are controlled by 2-O- and 6-O-sulfated heparan sulfate. J Biol Chem 286:14435-14444. CrossRef Medline

Qu X, Pan Y, Carbe C, Powers A, Grobe K, Zhang X (2012) Glycosaminoglycan-dependent restriction of FGF diffusion is necessary for lacrimal gland development. Development 139:2730-2739. CrossRef Medline

Ramsbottom SA, Maguire RJ, Fellgett SW, Pownall ME (2014) Sulf1 influences the shh morphogen gradient during the dorsal ventral patterning of the neural tube in xenopus tropicalis. Dev Biol 391:207-218. CrossRef Medline

Rubin AN, Alfonsi F, Humphreys MP, Choi CK, Rocha SF, Kessaris N (2010) The germinal zones of the basal ganglia but not the septum generate GABAergic interneurons for the cortex. J Neurosci 30:12050-12062. CrossRef Medline

Shimokawa K, Kimura-Yoshida C, Nagai N, Mukai K, Matsubara K, Watanabe H, Matsuda Y, Mochida K, Matsuo I (2011) Cell surface heparan sulfate chains regulate local reception of FGF signaling in the mouse embryo. Dev Cell 21:257-272. CrossRef Medline

Shu T, Richards LJ (2001) Cortical axon guidance by the glial wedge during the development of the corpus callosum. J Neurosci 21:2749-2758. CrossRef Medline

Shu T, Sundaresan V, McCarthy MM, Richards LJ (2003) Slit2 guides both precrossing and postcrossing callosal axons at the midline in vivo. J Neurosci 23:8176-8184. CrossRef Medline

Smith KM, Ohkubo Y, Maragnoli ME, Rasin MR, Schwartz ML, Sestan N, Vaccarino FM (2006) Midline radial glia translocation and corpus callosum formation require FGF signaling. Nat Neurosci 9:787-797. CrossRef Medline

Sousa VH, Miyoshi G, Hjerling-Leffler J, Karayannis T, Fishell G (2009) 
Characterization of Nkx6-2-derived neocortical interneuron lineages. Cereb Cortex 19:i1-10. CrossRef Medline

Stanford KI, Wang L, Castagnola J, Song D, Bishop JR, Brown JR, Lawrence R, Bai X, Habuchi H, Tanaka M, Cardoso WV, Kimata K, Esko JD (2010) Heparan sulfate 2-O-sulfotransferase is required for triglyceride-rich lipoprotein clearance. J Biol Chem 285:286-294. CrossRef Medline

Toyoda R, Assimacopoulos S, Wilcoxon J, Taylor A, Feldman P, SuzukiHirano A, Shimogori T, Grove EA (2010) FGF8 acts as a classic diffusible morphogen to pattern the neocortex. Development 137:3439-3448. CrossRef Medline

Turnbull J, Powell A, Guimond S (2001) Heparan sulfate: decoding a dynamic multifunctional cell regulator. Trends Cell Biol 11:75-82. CrossRef Medline

Wallace VA, Raff MC (1999) A role for sonic hedgehog in axon-to-astrocyte signaling in the rodent optic nerve. Development 126:2901-2909. Medline

Wang Y, Kim E, Wang X, Novitch BG, Yoshikawa K, Chang LS, Zhu Y (2012) ERK inhibition rescues defects in fate specification of Nf1-deficient neural progenitors and brain abnormalities. Cell 150:816-830. CrossRef Medline

Xu J, Lawshe A, MacArthur CA, Ornitz DM (1999) Genomic structure, mapping, activity and expression of fibroblast growth factor 17. Mech Dev 83:165-178. CrossRef Medline

Yan D, Lin X (2009) Shaping morphogen gradients by proteoglycans. Cold Spring Harb Perspect Biol 1:a002493. CrossRef Medline

Yu SR, Burkhardt M, Nowak M, Ries J, Petrásek Z, Scholpp S, Schwille P, Brand M (2009) Fgf8 morphogen gradient forms by a source-sink mechanism with freely diffusing molecules. Nature 461:533-536. CrossRef Medline

Zhang H, Newman DR, Sannes PL (2012) HSULF-1 inhibits ERK and AKT signaling and decreases cell viability in vitro in human lung epithelial cells. Respir Res 13:69. CrossRef Medline

Zhang X, Bao L, Yang L, Wu Q, Li S (2012) Roles of intracellular fibroblast growth factors in neural development and functions. Sci China Life Sci 55:1038-1044. CrossRef Medline 